\title{
Opportunities AND Challenges FOR INTERDISCIPLINARY RESEARCH
}

\author{
Duane F. Alwin And Scott M. Hofer
}

$\sigma^{\prime}$ ome years ago, Thomas Kuhn (1962) pointed out that science advances in one of two main ways. First, by focusing on the problems and puzzles defined by existing paradigms, and by training students in the somewhat rigid methods and models of our disciplines, science inevitably makes progress by filling in gaps in knowledge and refuting existing hypotheses. Kuhn referred to this as "normal science," and it constitutes the major mechanism by which scientists produce knowledge that supports contemporary models of the phenomena of interest. Second, in addition to this mode of activity, science progresses by developing fresh approaches, by shifting the paradigms, or by repudiating the past through more dramatic scientific revolutions. Kuhn's work suggests that many of the most important developments in scientific theories and models over past centuries originated through the kind of paradigm shifts implied by this second mechanism.

Innovative advances in science promote the development of new communities that foster change and define progress in new ways. As long as the consensual processes of science accept the validity of given models and dominant theoretical perspectives, the paradigms on which they rest will more or less persist. However, as models begin to fail in their ability to describe empirical reality, they will eventually fall into disrepute, even when there is strong institutional pressure in support of such models. ${ }^{1}$ Moreover, old models are often vulnerable to more careful examination when they are subjected to the scrutiny that is possible with new and more refined methods of measurement and analysis.

\section{Assessing Progress in Cognitive Aging Research}

We believe this is a useful model for laying the background for the consideration of the present body of knowledge about cognitive aging and for raising the question about where the field of cognitive aging research is going. How should we measure progress in the field of cognitive aging research? What are the "normal science" paradigms that dominate the area? What is wrong with these paradigms, and what is right with them? What are the standards we should use for assessing the progress and vitality of research on cognitive aging? What are the indications of paradigm shifts, if any, and how should we set priorities for the future of cognitive aging research? In other words, how do we assess what we know, 
and how we know it, and how do we decide what areas are the most important avenues for future discovery? These are the issues surrounding the chapters of this Handbook of Cognitive Aging, and in this regard it is perhaps valuable to place these chapters in a broader context of why these issues are important.

The issues addressed by authors of these chapters are highly relevant to the present historical context, given that major support for research on cognitive aging comes from the federal government, namely the National Institute on Aging (NIA). The NIA places a high priority on supporting research on cognitive aging and has actively stimulated the development and review of research in this area (see National Research Council [NRC], 2000). The National Advisory Council on Aging explicitly mentions cognitive aging as a priority topic area for Behavioral and Social Research (BSR) program activities (NIA, National Advisory Council on Aging, BSR Program Review Committee, 2004), and the NIA Web site contains a number of documents underscoring its commitment to continue support the advancement of cognitive aging research.

At the same time, the NIA itself is taking the lead in examining the question of how to set priorities for funding of research in existing fields. The National Research Committee on Assessing Behavioral and Social Science Research on Aging, at the urging of the NIA, addressed the larger question of priorities for research funding. For example, what are the national priorities that govern the application of societal resources to the development of scientific knowledge? Are such decisions made by implementing any sort of rational evidence-based strategies? Or is it the case that the "decision processes of science agencies are unduly conservative in program and project selection" that fall short in terms of "converting research findings into usable and useful applications" (NRC, 2007, p. 9)? In keeping with these same criteria, the authors of the chapters in this handbook were asked to address the questions of not only "What do we know?" but also "What do we need to know?"

Thus, within the context of addressing the body of knowledge on cognitive aging, and from the point of view of developing funding for future research, it is useful in this context for the
NIA to inquire about the priorities across its various initiatives, and specifically about how it might make decisions of funding in the area of cognitive aging research. We ask these questions here not because we plan to explicitly address them but because of their general relevance to the issues posed by the chapters in this book. Given an interest in the future of cognitive aging research, and in anticipation of continuing levels of funding of research on cognitive aging, what are the questions the field should be asking, what kinds of measurement approaches and data resources should be brought to bear on them, and how should data be modeled and explained? Of course, in such an endeavor the first objective is one of summarizing the existing knowledge base and developing recommendations for further research.

Several years ago, the Committee on Future Directions for Cognitive Research on Aging of the NRC made a study of the state of our knowledge about cognitive aging. This study was commissioned by the BSR Program of the NIA, which encouraged the publication of The Aging Mind: Opportunities in Cognitive Research (NRC, 2000), edited by Paul Stern and Laura Carstensen. That report was eloquent in its summary of the current state of knowledge in the area of cognitive aging and its recommendations for future research. We return subsequently to a brief discussion of the findings of the Committee on Future Directions for Cognitive Research on Aging and the committee's recommendations, but first we mention some of the reasons for emphasizing the need to focus on a greater understanding of cognitive aging and the importance of considering the future of cognitive aging research. The authors of The Aging Mind stressed the need for further investments in new types of research, particularly through a wider-angle interdisciplinary lens, that will enhance our present level of knowledge.

Specifically, there are several areas in which there is a need for greater investments in cognitive aging research and a pressing need to know more. One of the most important phenomena, often used to justify the investment in new knowledge about cognitive aging, is the phenomenon of population aging. This refers to the demographic fact of life that for several decades 


\section{4 - INTRODUCTION}

the population has been getting older and the seemingly inevitable prospect that this trend will continue into the first half of the present decade. Within the framework of population change, there are a number of additional questions one can pose regarding the applicability of present generalizations to future cohorts of aging persons (see chap. 4 , this volume).

The authors of The Aging Mind (NRC, 2000) stressed the fact that behavioral researchers have focused on establishing the classification of types of cognitive functioning and their relationship to age and on the measurement and tracking of these functions over the life span (see, e.g., Salthouse, 1999). At least since Cattell's early publications (1941), and developed further by Horn (1965; Horn \& Cattell, 1966), aging researchers have distinguished between two interrelated components of cognitive functioningfluid and crystallized abilities. The term fluid abilities refers to those functions that reflect the capacities for insight into complex problemsolving tasks, independent of sensory modalities and cultural settings, whereas crystallized abilities refers to those functions that result from the investment of fluid abilities in experience and culturally defined tasks (Cattell, 1971). The differing relationships to age of fluid and crystallized functions-fluid abilities tend to decline with age after reaching a peak in early life, whereas crystallized abilities tend to remain stable through to very old age-caution one against making broad generalizations about cognitive aging. It is important, therefore, to understand age-related trajectories of performance in terms of what is being measured. There is a great deal of support for the idea that there are several possible trajectories of the life span development of cognitive abilities, and there is clearly a need for more information on the nature of age-related change along multiple dimensions for welldefined populations. In addition, there are several other urgent matters, which we briefly discuss in the following section, involving the inevitability of decline; the nature and patterns of these declines; the relationship between "normal" aging and dementia; the linkage between cognitive aging and several dimensions of health and sensory function; the role of cultural and social factors in cognitive change; and the potential for technological arrangements to assist with adaptation to cognitive change, which especially declines, in older age.

\section{Understanding Cognitive Aging}

Researchers have raised several hypotheses to explain declines in cognitive functioning with increasing age (e.g., see Brown \& Park, 2003; Park, 1999; and Park et al., 1996). Taking a somewhat broadly gauged approach, we see three types of theories that account for cognitive aging: (1) psychological theories of cognitive aging that stress underlying common causes accounting for a general cognitive decline with age, such as the hypothesis of generalized slowing or link with sensory acuity (e.g., Baltes \& Lindenberger, 1997; Baltes \& Mayer, 1999; Birren \& Fisher, 1995; Cerella, 1985; Craik \& Byrd, 1982; Lindenberger \& Baltes, 1994; Myerson, Hale, Wagstaff, Poon, \& Smith, 1990; Salthouse, 1993, 1996a, 1996b); (2) biological theories that stress overall agerelated declines in organ function, including neurological function, which lead to increases in the onset of illnesses or impairments, and risks of experiencing multiple illnesses or impairments, and which serve as exogenous influences on cognitive function (Waldstein, 2000; Waldstein \& Elias, 2001); and (3) sociological theories of disablement (Verbrugge \& Jette, 1994) and cumulative disadvantage (Dannefer, 1984, 2003), which posit that social processes account for health (including cognitive functioning) disparities and differences in rates of change. Not only do socioenvironmental inequalities impact individual differences at multiple time points over the life span, but also there is considerable theory suggesting that the residues of these influences in individual differences cumulate over time (Dannefer, 1987, 1988; O’Rand, 1996).

Obviously, these theories complement one another. Although disciplinary biases may tend to emphasize one or the other as relevant theory, an interdisciplinary approach will take all of them as relevant. As noted, the psychological theories attempt to identify and isolate critical unobserved cognitive processes, operations, or constructs that account for between-person differences in rates of cognitive change, whether it is processing speed, a generalized slowing, or declining cognitive reserve. The basic idea is 
that these underlying processes produce correlated rates of change, and although a number of approaches have been taken to verify these notions, one common approach to the empirical examination of these explanations relies on common factor models. In contrast to the common factor explanations, biological theories rely on explanations involving physical disease processes, which explain between-person differences in rates of change by directly measuring individual differences in the presence of chronic disease (e.g., cardiovascular disease, diabetes, or hypertension). Finally, the explanations that rely on the understanding of the role of social factors focuses on the measurement of betweenperson differences in social inequalities and the consequences of these for trajectories of cognitive functioning (see Alwin \& Wray, 2005).

\section{The Pressing Need to Know More}

As we noted earlier, the study of cognitive aging is a national priority, not only in the United States but in many other countries as well. There are a number of reasons why the current state of knowledge may not be enough to forecast future levels of cognitive aging for most people who are living today. Prominent among the major rationales for the pressing need to better understand the realities of cognitive aging is the worldwide phenomenon of population aging (Suzman, Willis, \& Manton, 1992). Given what is known about the demography of agingincreasing levels of population aging in the 21st century (United Nations, 2002) — the need to understand the population processes that are involved in cognitive aging are ever more pressing (Suzman, 2004).

\section{Population Cognitive Aging}

How do processes of population aging impact cognitive aging? Why is this essentially demographic phenomenon relevant to behavioral scientists who study cognitive aging? First, virtually all we know about cognitive aging was learned from studies conducted on persons born in the early part of the last century. If the arguments advanced by Warner Schaie and his colleagues (see Schaie, 1984; Schaie, Willis, \&
Pennak, 2005; Willis \& Schaie, 2006; also see chap. 23, this volume) are correct-that historical factors influence the nature of cognitive change-then it is reasonable to ask whether our current knowledge is applicable to the cohorts born after World War II (often referred to as the "Baby Boom" cohorts) and whether we can any longer entertain the idea that processes of cognitive aging revealed from past studies apply to these future cohorts. In short, to what populations does our present state of knowledge regarding age-related trajectories of cognitive performance apply?

One of the important components of population aging is declining mortality rates, and thus the naturally occurring question is whether old age can sustain cognitive function as well. Aging is not a disease process, but it does eventually produce both functional decline and increased susceptibility to illness and death from specific diseases. Signs of typical aging, such as short-term memory lapses, wrinkled skin, and gray hair are thus not considered symptoms of disease and need not result in greater susceptibility to death. However, with advanced age also comes weakened ability to fight off diseases such as cancer and infections, even as there is cognitive decline that reduces memory, speed of processing, and the like. When advances are made in curing or forestalling the diseases that tend to result in death to older people, then an even larger proportion of people survive into advanced old age (Finch \& Crimmins, 2004; Weiss, 1990).

On the other hand, the population may experience what Vaupel and Yashin (1985) termed an "apparent failure of success" (pp. 181-182). Health advances allow frailer, more susceptible individuals to live longer. Certainly, the best current estimates are that as the rapid growth in the oldest age group continues, so will the prevalence of the dementias, for example, Alzheimer's disease (AD; see Evans et al., 1992). This subpopulation will have a higher dementia rate at a given age than does a more robust subpopulation (consisting of people who would have lived to that age without the advances in health practices). Thus, although one may forestall physical functional decline and the susceptibility to illness and death from specific diseases, there may be no counterpart in 


\section{6 - INTRODUCTION}

the area of cognitive functioning. The question for the student of the future of cognitive aging is: Will changes in cognitive function continue in old age, as our current models predict, or will we be able to develop parallel remedies that cure or forestall cognitive functional decline? Some of the current literature indicates that cognitive impairment in older age is largely not currently preventable and that dementia, particularly $\mathrm{AD}$, will increase in prevalence in future years (Brookmeyer \& Gray, 2000; Brookmeyer, Gray, \& Kawas, 1998; Evans et al., 1992). Some suggest that the prevalence of $\mathrm{AD}$ in the next 50 years is projected to nearly quadruple, "which means that 1 in every 45 Americans will be affected by the disease" (Kawas \& Brookmeyer, 2001, p. 1160).

\section{The Inevitability of Cognitive Decline}

A second set of related concerns involving the importance of future research on cognitive aging is the question of the inevitability of cognitive decline. Although there is a large and growing theoretical and empirical literature documenting the declines in cognitive functioning across a number of performance domains, there is a great deal of heterogeneity in patterns of change in cognitive functioning as people age, and there is substantial evidence in some cognitive capabilities for stability and even growth. Although the authors of The Aging Mind concluded that the overall narrative of cognitive aging is one of decline and loss of function, they challenged the "popular notion that mental decline with age is inevitable, progressive and general," suggesting that "research presents a more complex picture" (NRC, 2000, p. 37). Several of the chapters in the present volume (e.g., chaps. $6,18,22$, and 34) also make the claim that cognitive decline in older age is not inevitable, citing a range of experiential and neuropathological risk factors that may produce individual differences in cognitive performance among older adults.

Moreover, recent work has suggested that "some cognitive processes decline almost inevitably even in healthy older adults," which has been attributed to "normal aging," but "past experience [in] geriatric research should leave room for skepticism about attribution of any functional decline to 'normal' processes" (Hendrie et al., 2006, p. 13). Hendrie et al. (2006) argued, for example, that even though "significant cognitive decline" is quite common in the older population, "individuals with cognitive decline are at much greater risk for having dementing disorders" (p. 13). This is a point of view that says there is really no such thing as "normal aging" when it comes to cognitive function. Cognitive declines that occur are instead reflecting some kind of "non-normal" processes that may have the possibility of being treated. The argument is that there is far too much attention placed on cognitive decline in research, rather than on "successful aging" (see Rowe \& Kahn, 1998). By reassigning meanings, this approach comes up with the concept of the "healthy aging brain" (Hendrie et al., 2006, p. 13). One of the interdisciplinary challenges that faces cognitive aging researchers involves the relationship among neural health, physical health, and cognitive function. Few, if any, studies have good measures of all three dimensions in longitudinal data.

\section{The Nature and Timing of Cognitive Decline}

Although there is admittedly disagreement with respect to the inevitability of cognitive decline, there is certainly heterogeneity in the experience of cognitive aging. Despite this, the overall aggregate trend for many dimensions of human abilities is one of decline. Individual differences aside, there is general agreement that there are systematic age-related declines in cognitive functioning in many performance domains from midlife (in some cases) and into older age. One early debates in the field of cognitive aging - between Paul Baltes and Warner Schaie on the one hand versus John Horn and Gary Donaldson on the other-involved the question of the typical levels of decline in cognitive function and the timing of that decline (see, e.g., Baltes \& Schaie, 1976; Horn \& Donaldson, 1977, 1980). Baltes and Schaie (1976) argued that much of early theorizing about systematic declines in cognitive abilities from midlife onward were in error and that many cognitive functions remained intact into very old age, challenging what they called the "myth of intellectual decline." Horn and 
Donaldson $(1977,1980)$ argued that this was in part an issue of what is being measured. Recalling the Cattellian duality - the distinction between fluid and crystallized abilities (Cattell, 1971) and the differing relationship of these two concepts to age, they argued that many fluid intelligence abilities experience declines from early adulthood through to old age. Horn and Donaldson (1980, p. 479) drew the conclusion from their data that with age there is a loss of neurological base for intellectual functions, and that loss is probably reflected most notably in performance measures reflecting fluid intellectual abilities.

Some of the best evidence for the life span development of various cognitive abilities is Schaie's (1996) Seattle Longitudinal Study (SLS; see also Salthouse, 1991), which began tracking a cross-section of the adult population in 1956 at 7-year reinterview intervals. Schaie's early work (1983) concluded, on the basis of 21 years of the SLS, that "reliably replicable age changes in psychometric abilities of more than a trivial magnitude cannot be demonstrated prior to age 60" (Schaie, 1983, p. 127). His more recent work has tended to bear out these conclusions (see Schaie, 1989, 1990, 1994, 1996; see also Hertzog \& Schaie, 1986, 1988; Schaie \& Hertzog, 1983), and he has made a strong case for stability in many measured abilities over most of the adult life span. Schaie and his colleagues have argued that there is relative stability of mean performance levels throughout most of the life span, with some decline in old age, due to the onset of the dementias and other disease-related impediments to complete cognitive functioning.

However, this seemingly straightforward problem of identifying the age at which change begins and the pattern of change in the population is actually quite complex and has not been fully resolved. Many of these methodological and sampling issues were well described in the early debate over this question of when change begins (Baltes \& Schaie, 1976; Horn \& Donaldson, 1977, 1980) and are further developed in many of the chapters throughout this handbook. Longitudinal studies, although they provide the essential measurement of withinperson change, require repeated exposures to cognitive tests, and this usually results in practice-related gains in performance in the opposite direction of age-related declines. Valgeir Thorvaldsson et al. (chap. 17) argue that these practice effects cannot be statistically controlled for in most longitudinal studies. Numerous other effects confound simple description of aggregate aging-related change and include cohort differences, differential mortality selection, initial sample selection, and health-related change.

\section{The Linkages Between Health and Cognition}

Researchers have raised several hypotheses to explain the apparent decline in cognitive functioning with increased aging. The first of these, which is popular among biological aging specialists, posits that cognitive decline is the result of a more general process of neurological decline that affects both cognitive and sensory functioning. A second set of explanatory factors involves overall age-related declines in organ function that lead to increases in the onset of illnesses or impairments and risks of experiencing multiple illnesses or impairments. Third, cognitive decline may be related to other age-related functional limitations, particularly in sensory function and physical health. Fourth, as discussed in the section titled "The Role of Social and Cultural Factors in Cognitive Aging," differences among age groups in levels of crystallized intelligence (measured by differences in schooling levels) may account for declines in measures of cognitive functioning and its covariates.

One of the dominant views in the literature, including the view of Paul Baltes and his colleagues, is that the sensory-cognitive function relationship reflects a general common factor underlying the aging process (e.g., Baltes \& Lindenberger, 1997; Lindenberger \& Baltes, 1994). Sensory impairments, particularly vision and hearing, are among the most prevalent agerelated functional conditions, with 1 in 7 middleaged adults and 1 in 4 older adults experiencing at least one impairment (Wray \& Blaum, 2001). However, how sensory impairments are related to cognitive test performance (however defined) is not yet clear, and recent research based on longitudinal data has provided very little support for this hypothesis (e.g., Anstey, Hofer, \& Luszcz, 2003a, 2003b; Anstey, Luszcz, \& Sanchez, 2001). Although vision and hearing appear to 


\section{8 • INTRODUCTION}

take different pathways to impairment, there are social as well as physiological losses to the extent that they diminish a person's ability to interact with his or her surrounding environment. The underlying mechanisms linking sensory and cognitive functioning, in particular, remain inconclusive, because of the sample selection and sample size limitations, overreliance on cross-sectional data (i.e., age differences), definitions of sensory and cognitive impairments, and controls used by the researchers (see Hofer, Berg, \& Era, 2003). Nonetheless, the findings are certainly suggestive, and more research is needed that includes precise measures of sensory and cognitive functioning with attention to the measurement commonality of sensory acuity and cognition due to testing material confounds as well as to the broader influences, such as disability and health, that may affect both systems.

In contrast to the common cause theories of cognitive aging, there is a great deal more evidence supporting the contingent role of biological factors in cognitive aging (see Waldstein's excellent summary of this literature in NRC, 2000, pp. 189-217). Chronic health conditions reflect serious limitations that may inhibit normal activities that promote the maintenance of cognitive function. Cognitive change has been linked to a number of chronic disease conditions, including cardiovascular disease (Geroldi et al., 2003; Hassing et al., 2002; Pavlik, Hyman, \& Doody, 2005), pulmonary function (Anstey, Windsor, Jorm, Christensen, \& Rodgers, 2003), type 2 diabetes (Cosway, Strachan, Dougall, Frier, \& Deary, 2001; Crooks, Buckwalter, \& Petitti, 2003; Hassing, Grant, et al., 2004; Hassing, Hofer, et al., 2004), stroke (Ostir, Raji, Ottenbacher, Markides, \& Goodwin, 2003), and depressive symptoms (Wilson, Mendes de Leon, Bennett, Bienias, \& Evans, 2004). Longitudinal data clearly are needed to assess the extent to which change in health conditions and disability status are linked to cognitive age-related change. These issues are important in their own right but also as a possible explanation of racial/ethnic and sex differences in cognitive change.

It is also well known that a positive association exists between positive health behaviors and indicators of morbidity and mortality. Cross-sectional research suggests several health-related lifestyle factors are linked to cognitive status, particularly nutrition (Corrêa-Leite, Nicolosi, Cristina, Hauser, \& Nappi, 2001), cigarette smoking (Hill, Nilsson, Nyberg, \& Bäckman, 2003; Kalmijn et al., 2002; Razani, Boone, Lesser, \& Weiss, 2004; Richards, Jarvis, Thompson, \& Wadsworth, 2003; Zhou et al., 2003), alcohol consumption (Britton, Singh-Manoux, \& Marmot, 2004; Espeland et al., 2005; Harris, Albaugh, Goldman, \& Enoch, 2003; Kalmijn, van Boxtel, \& Verschuren, 2002; Leroi, Sheppard, \& Lyketsos, 2002; Perreira \& Sloan, 2002; Schinka, Belanger, Mortimer, \& Borenstein-Graves, 2003; Zhang, Heeren, \& Ellison, 2005; Zhou et al., 2003), and physical activity (Churchill et al., 2002; Dik, Deeg, Visser, \& Jonker, 2003; Emery, Shermer, Hauchk, Hsiao, \& MacIntyre, 2003; Heyn, Abreu, \& Ottenbacher, 2004; Hillman, Belopolsky, Snook, Kramer, \& McAuley, 2004; Schuit, Feskens, Launer, \& Kromhout, 2001; Yaffe et al., 2003). Although the research is somewhat mixed, cigarette smoking is a risk factor for healthy cognitive functioning, the relationship of alcohol use seems to favor moderate drinkers, and there is little doubt that a physically active life is good for the brain. Some research ties the factors empirically to cognitive change (e.g., Chen et al., 2003), but in general longitudinal research is lacking. A great deal more research is needed to examine the interplay between cognitive aging and several additional components of health and well-being, particularly chronic disease conditions, lifestyle or health behaviors, and functional status.

\section{Neural Decline Versus Disease Processes}

The above-reviewed research dealing with chronic disease and cognitive function has typically not explicitly dealt with neurological disease, as opposed to chronic "physical disease" and lifestyle or health promotion factors. Dementia, particularly AD, is one of the major causes of disability and declining function and quality of life among the oldest in the population (Kawas \& Brookmeyer, 2001). It is thought to be the result of a disease process, as are other outcomes classified as resulting from dementia (see Wilson, Bennett, \& Swarzendruber, 1997). From a disciplinary perspective, the study of cognitive aging and dementia has proceeded independently. Researchers who study AD and 
other dementias almost exclusively deal with patient populations that have been diagnosed; little research is aimed at the precursors of the diseases processes that presumably lead to a clinical diagnosis. On the other side, researchers interested in understanding what they consider "normal" or "healthy" aging do not always explicitly deal with neural patterns thought to result from disease processes. Often researchers interested in "normal aging" attempt to eliminate the influence of dementia by screening out impaired individuals with mental status examinations. This strategy is only partially successful, and even in select, highly screened samples of older adults a substantial proportion of older participants may be at the very early stages of preclinical dementia and influence cognitive estimates of cognitive performance and age effects.

This problem of the influence of preclinical dementia would likely be amplified in a more representative sample of elders, compared with self-selected volunteer samples of motivated individuals. Recent studies have shown that the presence of subgroups with preclinical dementia can influence estimates of cognitive change and the covariance of change among cognitive domains (Sliwinski, Hofer, \& Hall, 2003; Sliwinski, Hofer, Hall, Bushke, \& Lipton, 2003). Moreover, in the absence of dementia and disease (Haan, Shemanski, Jagust, Manolio, \& Kuller, 1999; Hall, Lipton, Sliwinski, \& Stewart, 2000; Rubin et al., 1998) there is very little evidence of cognitive loss and, if present, is very slight. This problem of preclinical dementia is an illustration of why attempts to study "healthy" populations may be misguided and strongly argues for the simultaneous measurement of neurological and behavioral patterns and processes.

\section{The Role of Social and Cultural Factors in Cognitive Aging}

As several of the perspectives articulated in this volume suggest, there are a number of social, cultural, and historical factors - otherwise known as contextual factors-that are known to interact with processes of cognitive aging. For example, The Aging Mind includes an appendix prepared by Shinobu Kitiyama, which makes an argument about the implications of cultural variations in cognition for the experience of cognitive aging (NRC, 2000, pp. 218-237). There is little question that social context plays a role in cognitive aging, not only in terms of the average trajectories of cognitive change within contingent conditions of cultural life experience but also with respect to within-culture individual differences in patterns of aging. Kitayama (2000, pp. 219-221) argued that the field of "cultural psychology" has much to offer the study of cognitive aging. The examination of cross-cultural data on age-related change in cognitive function represents one of the important challenges for future research.

In addition to cultural values and definitions of normative changes connected to the life cycle, sociological theories emphasize the processes by which disabilities or disadvantages cumulate over time. Indeed, the life span developmental perspective on social status and health challenges many assumptions about the static nature of the effects of social inequalities on health (Alwin \& Wray, 2005). This perspective emphasizes that social status factors (education, economic resources, sex, race/ethnicity) have an impact on health (in this case, cognitive functioning) at multiple points across the life span and that the effects of social inequalities may accumulate over time (Dannefer, 1987, 1988; O'Rand, 1996; Verbrugge \& Jette, 1994). Research on social resources and cognitive function shows that there are linkages with social networks, social engagement/activity, and social support (see chap. 36, this volume).

Level of schooling is often taken to be a generalized measure of social resources that condition the development of the level and the degree of change in cognitive functioning. There has been some debate about whether the amount of schooling should be controlled in assessing age-gradients in cognitive functioning. Lorge (1956) and Bandura (1989) have suggested that researchers investigating patterns of cognitive aging may profitably consider the importance of controlling for schooling in examining the nature and patterns of cognitive aging (see also Birren \& Morrison, 1961). Salthouse (1991), in contrast, suggested researchers could effectively ignore schooling in the study of cognitive aging. He articulated four reasons for not taking age group differences in schooling into account: (1) schooling is both a cause and a consequence 


\section{0 - INTRODUCTION}

of abilities; (2) units of education have changed their meaning over time; (3) there have been historical changes in the opportunities to acquire more education; and (4) even when age-gradients in cognitive functioning are adjusted for age group differences in schooling, variation in education can account for no more than a small proportion of the age differences observed in certain measures of cognitive functioning (Salthouse, 1991, pp. 74-77). By contrast, the work of Alwin et al. (2008) on cohort effects found that it is important to adjust for differences among cohorts for intercohort differences in schooling; however, doing so accentuates some of the differences among cohorts (see chap. 4, this volume). Cohort differences in schooling act as a suppressor to assessing the true levels and rates of change within cohorts, so by not controlling for both cohort differences and schooling in assessing within-person change one can arrive at a mistaken specification of the aging-related function of cognitive change (see Alwin et al., 2008).

In addition, a literature has developed around the question of whether higher levels of schooling act as a protective factor in cognitive aging by retarding the rate of change in cognitive decline and therefore acting to buffer the processes of normal aging (e.g., see Anstey \& Christensen, 2000; Christensen et al., 2001, 1997; Dufouil, Alpérovitch, \& Tzourio, 2003). The results of this body of research are mixed, with some studies showing no interaction of schooling and rates of change and others finding such a buffering effect. Alwin et al. (2008) showed, using data from the Health and Retirement Study (HRS), and analyzing this issue separately by cohort, that there is little evidence that schooling significantly affects the rate of cognitive change. This research is summarized in Chapter 26 of this volume.

\section{Technological Supports for Adaptation to Cognitive Aging}

There a need for a great deal more research on the role of social and cultural factors in shaping the environmental influences on the experience of cognitive aging, in part because such research has the potential to lead to experiential interventions that can alter the course of cognitive aging. Indeed, this is one of the primary areas where the NRC report (2000, pp. 35-36) emphasized the need for additional research. The appendix chapter of The Aging Mind by Fisher (2000, pp. 166-188) focuses on adaptive technologies that may provide assistance in cognitive functioning. In addition, considerable research has been designed to demonstrate that intervention in the form of cognitive training can produce a salutary change in cognitive functioning (e.g., Willis, 1990; Willis et al., 2006). As Horn and Donaldson (1980, pp. 516-517) advocated, however, such intervention studies require a rigorous approach to assessment and intensive engagement in stimulating activities, and the methodological requirements of such studies are rarely met.

\section{The Interdisciplinary ChalLENGE}

We believe that the scope of the challenge for future research on cognitive aging involves not only coming to terms with the nature of developmental processes and the social, cultural, and demographic realities of population aging but also the need to foster new interdisciplinary research agendas in the pursuit of knowledge of cognitive aging. The authors of The Aging Mind emphasized the need for interdisciplinary approaches that develop a comprehensive theoretical framework that incorporated age-related variation in environmental factors, age-related changes in sensory function and health, and the interaction of these factors with neurological changes in development. They proposed a conceptual system that focused on three interacting systems: "cognitive structures and processes, neural health, and behavioral context, including task structure and social, cultural, and technological factors" (NRC, 2000, p. 9). The committee summarized the importance of this conceptual system in the following way:

Older people adapt to changes in their nervous systems and their environments and, at the same time, both types of changes affect their ability to perform cognitive tasks. To separate the various causes of cognitive change, it is necessary to examine inter- and intraindividual differences in cognitive function in both cross-sectionally and over time to identify patterns. Such examinations 


\section{Opportunities and Challenges for Interdisciplinary Research • 11}

should highlight the roles of dynamic adaptive processes, including changes in neuronal structure and function and in behavioral and social factors (e.g., social opportunity structures, the individual's routines and physical environment, the individual's goals, and the use of social and technological supports) that codetermine an individual's ability to function effectively. (NRC, 2000, pp. 10-11)

This is a valuable framework for setting the agenda of the future of cognitive aging, because it highlights the multiple components of the cognitive aging process.

Arguing that the ultimate focus of research on cognitive aging should be on the conjunction of factors that shape performance of activities of living (NRC, 2000, pp. 9-11), the NRC committee articulated the developments in knowledge across different subdisciplines that focus on $\operatorname{cog}$ nitive aging. However, despite the impressive claims that are made in this report with respect to what is known in the field of cognitive aging, the NRC committee also stressed the need for several major research initiatives that would contribute to the improvement of knowledge regarding age-related change in cognitive functioning. They identified three major areasneural health, cognition in context, and the structure of the aging mind-in which scientific developments are "creating significant opportunities for breakthroughs," and they urged the NIA to undertake major research initiatives that would (a) build the scientific basis for promoting neural health in the aging brain; (b) to understand the effects of behavioral, social, cultural, and technological context on the cognitive functioning and life performance of aging individuals; (c) to improve the understanding of the structure of the aging mind, including the identification of mechanisms at the behavioral and neural levels that contribute to age-related cognitive change; and (d) build the knowledge needed to intervene effectively in sociocultural contexts to assist individuals' functioning and performance (NRC, 2000).

Cognitive aging is the result of a number of factors working in combination, and the NRC committee stressed the importance of interdisciplinary forms of research. They encouraged the NIA to establish funding mechanisms that would challenge cognitive scientists from a multiplicity of disciplines to work together to solve the problems of understanding how these several factors jointly contribute to cognitive aging. There have been some efforts in these directions, although these developments have been limited in scope and activity. In 2001, the NIA held a workshop on "Cognitive and Emotional Health: The Healthy Brain Workshop," jointly sponsored with the National Institute of Mental Health and the National Institute of Neurological Disorders and Stroke. The purpose of the workshop was to discuss research concerning determinants of cognitive, emotional, and mental health among adults. It brought together selected leaders in the field for substantive discussions about the current status of existing knowledge, the potential value of secondary data analyses of existing data, the need for further instrument development to facilitate future studies, and potential designs of large studies that might be undertaken in the future. An international group of approximately 35 senior investigators attended, together with a large number of staff members from the National Institutes of Health (see Hendrie et al., 2006). ${ }^{2}$

Now known as the Cognitive and Emotional Health Project, this project has resulted in several findings and additional recommendations. The goal of this project was to "assess the state of longitudinal and epidemiologic research on demographic, social, and biological determinants of cognitive and emotional health among adults, and to determine how these pathways reciprocally influence each other" (Hendrie et al., 2006, p. 15). The project reports that there are 27 longitudinal data sets that include measurement protocols for both cognitive function and emotional health, meeting certain criteria of substantive and methodological importance (see Hendrie et al., 2006, p. 16). Another strategy for integrating longitudinal studies of aging is through active cross-study collaboration and coordination of analyses (see chaps. 27 and 40 of this volume, which describe the Integrative Analysis of Longitudinal Studies of Aging research network). Finally, the Cognitive and Emotional Health Project assembled an evaluation study committee, which was appointed to assess the state of epidemiological knowledge on the demographic, social, and biological determinants of cognitive and emotional health. This review of the evidence identified 


\section{2 • INTRODUCTION}

several risk factors consistently with cognitive outcomes and considerable overlap in findings across the domains of cognitive function and emotional well-being (Hendrie et al., 2006, pp. 19-21).

\section{The Present Volume}

This volume is the result of the International Conference on the Future of Cognitive Aging Research, supported by the NIA, which made an attempt to push for scientific revolutions in the area of cognitive aging research. The conference focused on the present state of knowledge on cognitive aging but stressed the importance of the development of a shared multidisciplinary agenda for future work in this area and the next steps to accomplish this. The questions that were addressed by the conference, and ultimately by the chapters in this volume, were aimed at boldly pushing the limits of what we know about cognitive aging and examining the epistemological basis of "How do we know what we know?" In the remainder of this chapter, we develop a framework for organizing multidisciplinary research on cognitive aging and for coming to terms with the factors that either contribute to or forestall the likelihood of new discoveries in the area of cognitive aging (see NRC, 2007).

By building upon the recommendations of The Aging Mind, this handbook explicitly focuses on an examination of the future of cognitive aging research. The chapters contained in this volume push this set of issues further, by critically evaluating the practical, methodological, and theoretical questions involved in translating the report's recommendations into concrete research plans. They were developed against the background of the issues we defined as critical for the future study of cognitive aging as follows:

Where do we want to be as a field in 25 years? What do we need to know about cognitive aging, and what are our plans to meet those needs? What theoretical breakthroughs are needed? How can we encourage those breakthroughs?

What are the interdisciplinary challenges that must be met to accomplish these aims? What novel research opportunities are necessary to link social science, behavioral science, cognitive science, and neuroscience approaches to cognitive aging?

From a demographic perspective, population aging is a fact. What can we predict about the nature of population cognitive aging? Given what we know about cognitive aging, can we predict the prevalence of various types of functional problems? Can we know the parameters of relevant aging functions for populations of interest?

Can we use past research and past models of cognitive aging to make predictions about the cognitive status of individuals and of the population at any point in the future? Are studies focusing on cross-sectional age differences adequate for understanding aging? Can the emerging research literature that focuses on individual-level change be used for making predictions about future cognitive functioning in individuals and the population?

What future research and research designs will be necessary? Are current methods for research adequate for developing the types of knowledge we envision for the future? Is there any good argument for changing the epistemological basis of the ways we have approached building empirical knowledge?

What new types of data are needed to build the kinds of knowledge we anticipate will need to be developed? Is there a need for new databases that can promote the needed developments in the field of cognitive aging?

How can mechanisms for data sharing promote a higher quality of science? Is there a constituency for the development of new models for scientific discourse among cognitive aging researchers?

This list is not exhaustive of issues that were raised by the papers in the conference, but they were the key focus of the papers commissioned for the conference and published in this book. There are a number of more specific methodological issues that are also addressed. For example, there are potentially serious limitations in the dominant methods of research on cognitive aging that pose threats to the validity of projections about the future of cognitive aging in the U.S. population and cross-nationally over the next several decades. The conference aimed to explore each of these domains with an eye toward developing a shared agenda for the next 
few decades of research on cognitive aging that will begin to implement the recommendations of the NRC report.

\section{Organization and Content}

The seven topical divisions around which we have organized the chapters in this volume are as follows: (1) substantive and theoretical reviews of what we know about cognitive aging, with the objective of developing an integrated theoretical perspective; (2) past and future dimensions of cognitive aging (areas covered include attention, memory and encoding, prospective memory, cognitive control, sensory function, everyday problem solving, expertise and knowledge, health and cognitive aging, and behavioral genetic perspectives); (3) biological dimensions of aging and the relationship of health-related processes; (4) historical processes and cultural differences; (5) developments in longitudinal design and measurement of cognitive impairment and functioning; (6) integrating social, demographic, and developmental perspectives; and (7) future directions for research on cognitive aging. Within each of these major sections the themes of the chapters cut across these broad set of issues we discussed in the previous section. Common to all the chapters in this handbook is that they raise concerns critical to the future of cognitive aging research, including theoretical and empirical issues and methodological critiques of design attributes of the current state of research.

\section{Part II: Integrative Theoretical Perspectives}

Cognitive function is an essential component of health and well-being across the life span. The understanding of the relationship of aging to cognitive function is a national priority because of its intrinsic relevance to the lives of aging members of society. In this section we have put together several chapters that deal with major theoretical perspectives on age-related changes in cognitive function. The opening chapter, "Theoretical Approaches to the Study of Cognitive Aging: An Individual-Differences Perspective," by Christopher Hertzog, provides a broad perspective on theoretical approaches to cognitive aging. In this chapter, Hertzog argues that what is needed is "better gerontological theory, along with better integration of such theory with the formulation and testing of explanations for age-related cognitive change." $\mathrm{He}$ makes a number of distinctions between concepts that frame research and thus explanatory theories of changes in cognition with age. Throughout this chapter, numerous examples are provided that highlight the interactive role of theory and methods for progress and innovation and the need for interdisciplinary approaches to understanding cognitive aging.

Keith Widaman provides a chapter on "Integrative Perspectives on Cognitive Aging: Measurement and Modeling With Mixtures of Psychological and Biological Variables." In this chapter, Widaman argues that fundamental accounts of cognitive aging, in terms of linking changes in the brain and psychological measures, rests on weak, indirect evidence but that real innovations and advances in understanding agerelated changes in terms of biological processes are possible by taking advantage of recent developments in measurement, design, and statistical modeling. Optimal measurement is an essential feature of an integrative science; however, trade-offs are often made, such as the use of short forms, that are detrimental to the goals of linking and understanding complex age-related processes. To move beyond being "theory rich, but data poor" because of our inability to disconfirm theories properly, Widaman encourages an emphasis on the substantive magnitude of results (not just statistical significance), attention to nonlinear trends and complex interaction hypotheses, and increased attention to both individual differences and average trends in interdisciplinary integrative research that includes biological process variables.

Chapter 4, "Population Processes and Cognitive Aging," by Duane F. Alwin, Ryan J. McCammon, Linda A. Wray, and Willard L. Rodgers, takes a somewhat different tack. These authors discuss four key issues for research on cognitive aging from a demographic perspective: (1) the need to specify models of aging for welldefined populations, (2) the phenomenon of population aging and its consequences for understanding future population levels of the prevalence of low cognitive functioning, (3) the possibility of cohort effects on estimates of functions 


\section{4 - INTRODUCTION}

that describe typical processes of cognitive aging, and (4) the problem of unmeasured heterogeneity in cohort-specific aging functions resulting from the phenomenon of mortality selection. Drawing examples from their ongoing analyses of cognitive aging in data from the Health and Retirement Study, a national probability sample of cohorts born from pre-1900 to 1947 , they report projected increases in levels of prevalence of low cognitive functioning through 2050, resulting from processes linked to population aging (see Alwin et al., 2008). An examination of cohort-specific slopes and intercepts in latent growth curve models of cognitive aging functions suggests the existence of significant differences, net of schooling, in cohort-specific intercepts in functions describing typical patterns of cognitive aging. One explanation for these cohort differences in intercepts is mortality selection, given the heterogeneity among existing cohort survivors in susceptibility to death and disease, a possibility that is explored in the chapter. The authors propose that controlling for cohort differences in expected age at death reduces the observed differences in intercepts and that it may therefore be important to account for heterogeneity in cohort experiences_-including not only residues of historical experiences but also variables linked to survivorship, especially mortality selection - in both cross-sectional and longitudinal studies of cognitive aging.

In his chapter on "Consequences of the Ergodic Theorems for Classical Test Theory, Factor Analysis, and the Analysis of Developmental Processes," Peter C. M. Molenaar describes explicitly the required conditions and limitations of an individual-differences approach for building a science of developmental and aging-related processes. In the area of cognitive aging, designs focusing on differences across people varying in age provide the majority of evidence for understanding aging. The concept, and indeed assumption, of ergodicity implicitly underlies inferences from this majority of research on individual age differences and is arguably unlikely to hold in practice given the rigorous conditions that must be met. Molenaar's chapter is inspirational and calls for a refocus on within-person change and variation, the essential and fundamental basis for making inferences regarding aging-related processes.
In the last chapter of Part II, Dale Dannefer and Robin Shura Patterson write from a sociological perspective about the limits and possibilities of cognitive aging research. They provide a critique of the philosophical assumptions often made about the phenomenon of cognitive aging, issues related to its conceptualization, and its even existence. This chapter is a provocative evaluation of both the social construction of aging and the current state of cognitive aging research. Its assessment of the current state of cognitive aging research, undertaken from a sociological perspective, raises a number of questions about the role of a "science of cognitive aging" in a society where "age-ism" is embedded in the institutionalized life course. As Dannefer and Patterson argue, a sociological perspective insists on understanding the origins of cognitive aging not only in organismic terms but also experiential and social terms, especially with regard to how expectations about cognitive aging are developed. The chapter is organized around three main arguments: (1) a consideration about how cohort analysis compels a rethinking of the determinants of cognitive aging; (2) the consideration of the distinctly human dimensions of cognition, including the inherent tendency for flexibility; and (3) a "social constitutive" interpretation of age differences in cognitive functioning. The authors conclude that the study of cognitive aging is at an early point in its development, and they suggest that until a paradigm shift occurs and until "the irrepressible and powerful dynamics" of the "social-constitutionalist paradigm" are recognized and embraced, little progress will be made in the study of cognitive aging.

\section{Part III: Dimensions of Cognitive Aging}

One of the most important research questions in the area of cognitive aging involves the nature of the differences among various ability domains in their trajectories of growth and change (Dixon, 1999). The strongest evidence for the link between aging and cognitive declines comes from studies examining declines in perceptual speed and memory in older age. These studies suggest that declines in cognitive performance are probably linked to declines in processing and sensory abilities in older adults, 
although much of this research has been based on cross-sectional designs. In other areas, such as verbal knowledge, declines appear not to be age related but may be explained by decrements in adaptive sensory function (Park, 1999). The chapters in this section of the book focus on aspects of cognition including attention, speed of processing, memory, encoding, cognitive control, expertise and knowledge, prospective memory, and so on.

The chapter by Joan M. McDowd and Lesa Hoffman, "Challenges in Attention: Measures, Methods, and Applications," provides an account of current knowledge and next steps for measurement development of attentional processes. Attention is fundamental to other cognitive processes and a key factor related to other functional outcomes, such as activities of daily living, in older adults. However, these same studies that demonstrate the importance of attentional processes also provide evidence that more sensitive measures of attention are needed to identify deficits earlier and permitting refined examination of the role of attention in other change processes. McDowd and Hoffman call for an integration of experimental and psychometric approaches for developing precise measures of attentional processes for identifying between-person age differences and within-person age changes and increased application of such assessment tools to real world applications involving aging-related processes and neurological diseases.

In the chapter by Paul Verhaeghen and John Cerella, "Everything We Know About Aging and Response Times: A Meta-Analytic Integration," a broad literature on response times is reviewed through the lens of previous meta-analyses and synthesized. The findings across the many studies of response times are complex but appear to arrange into distinct types of measures exhibiting differential age trends, with lexical tasks showing least effects of age differences, simple response times with modest slowing, and spatial tasks showing the greatest age-related deficit. The insightful and integrative nature of this review and appraisal of results to understanding aging and response times provides a model for theory development in other domains.

Susan R. Old and Moshe Naveh-Benjamin provide a chapter on "Age-Related Changes in Memory: Experimental Approaches" and summarize some of the major empirical evidence for age-related deficits in distinct types of memory performance, providing descriptions of key studies that detail distinct aspects of memory functioning (e.g., implicit vs. explicit memory) and encoding, retention, and retrieval processes. Several theoretical approaches for explaining aging-related deficits in memory performance are discussed, including speed of processing, working memory capacity, and attentional resources. Old and Naveh-Benjamin call for greater integration of basic memory processes and encourage increased emphasis on the practical application of knowledge of both positive and negative factors affecting memory performance from such research.

Mark A. McDaniel and Gilles O. Einstein focus on self-initiated retrieval processes in their chapter, "Prospective Memory and Aging: Old Issues and New Questions." In this chapter, they discuss research on prospective memory, involving the performance of an intended action at an appropriate time or in response to a particular cue in the future. In their view, multiple processes underlie successful prospective memory performance, including strategies that involve controlled monitoring for the target event and spontaneous retrieval mechanisms. McDaniel and Einstein identify challenges and promising avenues for this important area of research that has many real life applications and potential for interventions to maintain functioning in older adults.

Susan Kemper and Joan M. McDowd emphasize task decomposition approaches for understanding frontal lobe function in their chapter, "Dimensions of Cognitive Aging: Executive Function and Verbal Fluency." They describe research that aims to identify a set of component processes of executive function, such as inhibition, updating, time sharing, and switching, that will lead to better measurement of these component processes and permit an examination of how these processes change differentially over the life span and the mapping of these component processes onto other cognitive processes. This approach holds great promise for advancing our understanding of executive function and how aging-related neurological diseases affect semantic and executive functioning processes. 


\section{6 - INTRODUCTION}

In their chapter, "Executive Function in Cognitive, Neuropsychological, and Clinical Aging," Mary A. Luszcz and Anna P. Lane provide a description of the frontal hypothesis of cognitive change with age, emphasizing issues related to measurement and construct validity of neuropsychological measures of executive function. The role of the central executive is fundamental to conceptualizations of cognitive functioning, such as working memory, and is considered to include processes related to control and planning, inhibition, and task switching. Luszcz and Lane provide a succinct account of this approach and discuss challenges and future needs in this research area, particularly in regard to conceptual specification and measurement approaches and links to brain function and dysfunction.

Cynthia A. Berg discusses developments in the assessment of problem-solving capacity in demanding real life situations in her chapter, "Everyday Problem Solving in Context." Berg reviews the literature on this topic and provides succinct accounts of the motivation for this area of research and the theoretical perspectives that guide it, involving the similarity and utility of traditional psychometric tests and cognition in the context of older adults lives. Berg develops an integrative two-process model of everyday problem solving that combines the competency and contextual perspectives. Using this model, she identifies a number of challenges, including the development of a real-world criterion of success for validating measures of everyday problem solving; greater emphasis on intraindividual variability; and the integration of cognitive, affective, interpersonal, and physiological components that are relevant to everyday problemsolving capabilities.

Daniel Zimprich, Mike Martin, and Philippe Rast focus on dynamic aspects of memory performance in their chapter, "Individual Differences in Verbal Learning in Old Age." They discuss early developments in this area of research and the focus on learning curves for modeling performance gains over short intervals. They also describe and contrast a number of alternative formal models for population average and individual-level change in performance over repeated trials and provide an empirical example of such models in the Zurich Longitudinal Study on Cognitive Aging. This chapter provides important perspectives on modeling short-term change processes, with an emphasis on individual differences in learning, that will likely provide insight into cognitive processes affected by aging and health and may serve as more sensitive indicators of long-term change processes.

In their chapter on "Expertise and Knowledge," Neil Charness and Ralf T. Krampe discuss fundamental issues regarding the interplay among aging, knowledge, and expertise. They describe results that show that knowledge, though a strong predictor of performance, is limited by age-related declines on fundamental cognitive processes, such as those measured by speeded tasks. Charness and Krampe highlight several major challenges for research on knowledge and expertise, citing the long and demanding developmental period required for attaining expertise and the lack of congruence of this process to existing quasi-experimental designs used in most studies that would require longterm longitudinal studies of this important research domain.

\section{Part IV: Biological Indicators and Health-Related Processes}

Expanding upon the theme that health and cognition are inexorably linked, the chapters in Part IV provide coverage of current empirical and theoretical findings on the relation of biological factors in cognitive and related outcomes, and related physiological changes that are related to cognitive aging, including sensory and health-related changes. Authors of these chapters, as is true throughout this handbook, are the leaders in each respective area and are well versed in what we know and where the work in their area is moving.

Opening this section is a chapter by Avron Spiro III and Christopher B. Brady, "Integrating Health Into Cognitive Aging Research and Theory: Quo Vadis?" Spiro and Brady challenge us to identify health-related explanations for changes with age in cognitive functions-that "age" per se is not the causal factor or a useful approach for understanding or explaining cognitive aging. Although it is understood that the incidence of morbidity and comorbidity is increasingly related to chronological age and 
cannot be completely disentangled, a number of approaches and recommendations are made to better integrate health into explanations of $\operatorname{cog}$ nitive change with age. Spiro and Brady advocate the development of better measurement and standards for assessing health within studies on aging and provide several prescriptions for the study of health and cognition and the careful consideration of causal pathways of diseases that affect cognition.

The use of alternative temporal metrics to model and understand individual differences in change is discussed by Valgeir Thorvaldsson, Scott M. Hofer, Linda B. Hassing, and Boo Johansson in their chapter, "Cognitive Change as Conditional on Age Heterogeneity in Onset of Mortality-Related Processes and Repeated Testing Effects." In the study of aging-related changes, years of life remaining, in contrast to years since birth, often provides a better metric for the organization and understanding of individual and population change because of the increasing importance of health-related processes that are causing changes in cognitive and functional outcomes in later life. As in Spiro and Brady's chapter (chap. 16), Thorvaldsson and colleagues encourage analyses that are sensitive to aging and health-related changes simultaneously and point to the necessity of conditioning inferences regarding change to populations defined by both age and survival age. The identification of retesting effects can also confound inference regarding aging-related change, and they discuss important points regarding the design and analysis of longitudinal studies that by definition require repeated exposure to test material and the limitations of current statistical methods for disentangling such effects.

Dementia, particularly AD, is one of the major causes of disability and declining function and quality of life among the oldest in the population (Kawas \& Brookmeyer, 2001). From a disciplinary perspective, the study of cognitive aging and dementia has proceeded independently. Researchers interested in understanding "normal" or "healthy" aging attempt to eliminate the influence of dementia by screening out impaired individuals with mental status examinations. This strategy is only partially successful, and even in select, highly screened samples of older adults, a substantial proportion of older participants are in the very early stages of preclinical dementia and influence cognitive estimates of cognitive performance and age effects (e.g., Sliwinski, Lipton, Buschke, \& Stewart, 1996). This problem of the influence of preclinical dementia would likely be amplified in a more representative sample of elders, compared with self-selected volunteer samples of motivated individuals. Recent studies have shown that the presence of subgroups with preclinical dementia can influence estimates of cognitive change and the covariance of change among cognitive domains (Sliwinski, Hofer, Hall, Bushke \& Lipton, 2003). Moreover, in the absence of dementia and disease (Haan et al., 1999; Hall et al., 2000; Rubin et al., 1998), there is very little evidence of cognitive loss and, if it is present, is very slight. This problem of preclinical dementia is an illustration of why attempts to study "healthy" populations may be misguided.

In line with these conclusions, Robert $\mathrm{S}$. Wilson argues in his chapter, "Neurological Factors in Cognitive Aging," that age-related cognitive loss is not a normal outcome of old age but instead due to an accumulation of neuropathological lesions. He examines the evidence on the differential age-related susceptibility to neuropathologic lesions accumulating in different regions of the brain at different rates and argues against the common assumption that there is something called "normal aging" that is different from "abnormal aging" caused by disease. Instead, cognitive decline in old age results from risk factors linked to age-associated neuropathologic processes. On the assumption that prevention of cognitive loss is possible by tracing the linkage between risk factors and the neuropathologic pathways, he reviews the evidence for a number of neuropathologic lesions and concludes that these lesions, particularly AD pathology, are commonly found in the brains of older people who have no clinically recognizable dementia and that reflect age-related loss of cognition. He calls for the abandonment of the distinction between normal and abnormal cognitive aging and for a better understanding of the biochemical and molecular bases of vulnerability to age-related pathology in new areas of neurodeteriorative age-related change.

One of the strong recommendations of The Aging Mind report (NRC, 2000, pp. 14-20) was that the NIA should "undertake a major research 


\section{8 • INTRODUCTION}

initiative to build the scientific basis for promoting neural health in the aging brain." Neuroimaging is a rapidly developing field that continues to provide novel images of physiological indicators of brain function. In the chapter "Imaging Aging: Present and Future," Scott M. Hayes and Roberto Cabeza give a brief history of the study of neuronal loss inferred from cerebral blood flow and review recent advances in neuroimaging methods aimed at understanding the linkage between cognitive and cerebral aging. After reviewing the wide range of neuroimaging methods, including both structural and functional neuroimaging techniques, they conclude with suggestions for methodological integration that will further enhance our understanding of age-related cognitive and cerebral changes in older populations.

Kaarin Anstey's chapter, "Cognitive Aging and Biomarkers: What Do We Know, and Where to From Here?" draws together some of the emerging themes in cognitive aging that have focused on the relationship between cognitive aging and functional biomarkers, focusing primarily on sensory function, structural brain, and biochemical biomarkers. She observes that although some of the theoretical debates in this field tend to be circular and focus on statistical artifacts, the study of biomarkers and cognitive aging may help create bridges across disciplines that focus on differing functional indicators. She argues that multidisciplinary research teams will be required in future research of the linkages between cognitive and sensory change.

In agreement with Robert S. Wilson's conclusions, and responsive to the need for research on this topic, the chapter by Gwenith G. Fisher, Brenda L. Plassman, Steven G. Heeringa, and Kenneth M. Langa, "Assessing the Relationship of Cognitive Aging and Processes of Dementia," describes one ongoing effort that will help assess the relationship between "normal aging" and the clinical assessment of dementia. This is a project conducted by the Institute for Social Research in collaboration with Duke University and the Rand Corporation within the framework of the HRS (see Juster \& Suzman, 1995). This study comprises a clinical dementia assessment for a stratified subsample of $856 \mathrm{HRS}$ respondents to identify mild cognitive impairment, dementia, and its severity. This supplement-called the
ADAMS (Aging, Demographics and Memory Study) project-represents an effort to combine the strengths of survey-based measurement of cognitive function and the rigors of clinical assessments. The ADAMS project is the first nationally representative population-based study of dementia in the United States. The main goal of this chapter is to show how statistical models can be used to obtain estimates of the probability of dementia in older populations. Although the ADAMS data were not available for use in this chapter, the authors relied on data from the Veterans Study of Memory and Aging, which included a clinical assessment of dementia status, key cognitive status measures, and several demographic variables (e.g., age and schooling). The Veterans Study of Memory and Aging prediction equation was then used for purposes of imputing dementia status in the 1998 HRS sample. The authors speculate about how the clinical data from the ADAMS study will be used to study trajectories of cognitive aging in the HRS data.

\section{Part V: Historical Processes and Cultural Differences}

Although research has sought to develop generalizations about aging-related changes in cognitive functioning, it is clear that processes of aging do not occur in a sociohistorical vacuum. There are a number of social, cultural, and historical factors-often labeled contextual factorsthat are known to interact with processes of aging (e.g., Blanchard-Fields \& Hess, 1996; Fiske, Kitiyama, Markus, \& Nisbett, 1998). These issues are also addressed by the chapter by Denise C. Park, "Developing a Cultural Cognitive Neuroscience of Aging," in which the author develops a unique contribution focusing on cultural differences in neurocognitive function in old age. She points out that so far the agerelated patterns of neural functioning have been observed exclusively with Western samples of adults and that there is a need to investigate whether these neuron patterns are a general phenomenon with respect to culture or whether there are unique culture-specific patterns. She describes some of her preliminary research in this area, suggesting that culture moderates brain function, in that older Westerners have a greater bias for engagement of object areas, whereas 
older East Asians (from Singapore) focus more attention on background stimuli. This work opens up an entirely new set of exciting questions in the study of aging, culture, and the brain, which bid well to continue so into the future.

One of the important themes in the study of cognitive aging over the past four or five decades is the role of historical and cultural processes that impinge on processes of aging. K. Warner Schaie has pioneered the consideration of historical effects on cognitive functioning (see Schaie, 1984; Schaie, Willis, \& Pennak, 2005; Willis \& Schaie, 2006). The chapter by Warner Schaie in this volume, "Historical Processes and Patterns of Cognitive Aging," argues that marked cohort and generational differences potentially exist in levels and trajectories of cognitive abilities observed over the past century. The author argues that such patterns exist in the SLS data and that they are accounted for by cohort differences in educational and occupational achievements (see Schaie, 1996). The chapter is organized around the following four major sections: (1) a discussion of four different forms of aging found in the literaturewhat are called normal aging, successful aging, mild cognitive impairment, and dementia; (2) the presentation of a heuristic "co-constructionist" model for patterns of normal aging of cognitive function; (3) the description of historical events that have a bearing on differences in cohort experiences relevant to cognitive development; and (4) the presentation of results for measures of crystallized and fluid abilities that show the impact of historical processes that appear to be most relevant. The chapter concludes with some observations about the future course of changes in levels and rates of cognitive development.

The chapter on "Minority Populations and Cognitive Aging," by Keith Whitfield and Adrienne Aiken Morgan, provides further emphasis to the role of race/ethnicity as a structural force in developing cognitive resources and maintaining them. To understand the nature of race/ethnicity differences, one must develop comprehensive measurement of minority populations in research on cognitive aging. The inclusion of minority populations in studies of cognitive aging is important for several reasons. The demographic shifts toward greater representations of minority groups in the United States have given greater attention to the relevance of race/ethnicity to studies of health in general. Greater understanding of groups that have heretofore be underrepresented in studies of cognitive aging is important, and there are several challenges reflected in the investigation of minority populations. This chapter outlines many of the theoretical, conceptual, and methodological issues inherent in the study of the unique patterns of cognitive aging among African Americans and other minority populations. The chapter provides an overview of culturally appropriate models for the study of cognitive aging in minority populations and focuses on two key questions: (1) What patterns exist in the changes in cognitive abilities in older African Americans? and (2) what is the nature of variability in cognitive abilities among older African Americans? Factors that impinge upon possible differences of minority populationsfor example, health and socioeconomic statusare examined as critical contributions to levels and trajectories of cognitive aging among minority populations.

Finally, in the chapter by Jennifer J. Manly, "Race, Culture, Education, and Cognitive Test Performance Among Older Adults," she argues that assessments of cognitive impairment and daily functioning are susceptible to culturally dependent definitions and are quantified by measures that are sensitive to cultural and educational background. She draws attention to the cultural and educational factors that should be considered when assessing and interpreting cognitive function among older persons who are members of minority groups. She presents evidence from her own work that illustrates the observation that acculturation, quality of education, literacy, and racial socialization are potentially more meaningful than race/ethnicity in adjusting expectations for cognitive test scores and improving specificity of cognitive tests. She identifies specific issues that arise in the recognition of cognitive impairment and measurement of cognitive decline among these populations, including cultural bias in the neuropsychological measurement of cognitive function and differences in presentation of cognitively impaired elders across ethnic and cultural groups. Her work calls for greater clarity in the development 


\section{0 • INTRODUCTION}

of standards and guidelines for cross-cultural research on cognitive aging.

Developing his argument within the framework of environmental factors in cognitive development, the chapter by Duane F. Alwin, "Social Structure and Cognitive Change," introduces the idea that the theoretical consideration of social structure is an essential ingredient in linking cognitive aging to the environment. The concept of structure is central to virtually all schools of social scientific thought as well as many of the theories that are important for understanding processes of aging. It is generally agreed that the concept of social structure reflects a robust and persistent set of resources, opportunities, and constraints that impinge upon behavior and functioning across a wide range of domains relevant to aging. This chapter focuses on the linkage between social structure and cognitive function, particularly as it relates to aging, building on some of the prescient observations of Benjamin Bloom (1964) about the interaction of social environmental influences and cognitive change. Theoretically, differences in patterns of cognitive aging are linked to key elements of social structure. After the development of a theoretical framework that defines critical theoretical constructs-social structure, cognitive function, and aging-Alwin reviews the role of structural factors that contribute to levels and trajectories of change in cognitive function in older age. The principal focus is on the ways in which social structural factors-specifically, educational, socioeconomic, racial/ethnic, and gender factors-produce differences in levels and rates of change in cognitive function. The chapter provides several examples from contemporary research on structural factors and cognitive aging and concludes with some thoughts about how these issues can be usefully pursued in future studies.

\section{Part VI: Longitudinal Measurement and Analysis}

Virtually all quantitative social scientists agree that one of the most productive approaches to the study of aging and human development involves the collection and analysis of longitudinal data (see Alwin \& Campbell, 2001; Kraemer, Yesavage, Taylor, \& Kupfer, 2000). Although the bulk of the evidence on age-related differences in cognitive performance is based on crosssectional research, an increasing number of studies are longitudinal in design (Schaie \& Hofer, 2002). However, most of these studies span a relatively short period of time, often limiting the explanatory variables of cognitive change to static individual-difference variables or retrospective measurements that may be unreliable. More longitudinal research over lengthy periods of time is needed to confirm patterns of cognitive change in middle and older age. When combined with sampling designs that are adequate for the generalization of findings to populations of interests, new longitudinal investigations can take advantage of the significant improvements that have been made in studying change within individuals as they age.

There is an emerging consensus that longitudinal research is essential to the study of cognitive aging, and there are a number of completed and ongoing longitudinal investigations of adult development and aging in North America, Europe, Australia, and elsewhere that are providing important results in this regard. Although results from these studies have been steadily accumulating, the direct comparison of results across studies is often difficult given the variety of study designs, cultural and sampling differences, measurement instruments, and the particular statistical analyses performed. Indeed, meta-analyses of aging-related studies are based primarily on experimental or cross-sectional results with direct cross-study comparison of longitudinal studies only rarely performed. The first chapter in this section, by Andrea $M$. Piccinin and Scott M. Hofer, "Integrative Analysis of Longitudinal Studies on Aging: Collaborative Research Networks, MetaAnalysis, and Optimizing Future Studies," summarizes collaborative and coordinated efforts that have made use of longitudinal data for the analysis of cognition, health, and aging-related change. In addition to a focus on accumulating and cross-validating findings of within-person aging-related change, this chapter addresses theoretical, measurement, and statistical issues that arise in collaborative and comparative analysis. Piccinin and Hofer describe an international research collaboration, the Integrative Analysis of Longitudinal Studies on Aging, which seeks 
to optimize future research on cognition and health through careful measurement harmonization and coordinated analysis for cross-national comparison of key hypotheses regarding both between- and within-person aging effects.

Some of the most important quantitative developments in recent years for the study of aging are the advances that have been made in the modeling of growth (and decline) curves that allow researchers to study intraindividual change and its causes. In psychology, growth curve analysis grew out of the tradition of studying change scores. Although there are known problems with studying change scores between two points in time, growth curve approaches focus on trajectories of change across many observations, typically three or more points in time. The application of the growth curve approach now includes the ability to model intraindividual change in latent variables. The basic approach involves modeling the initial levels (or intercepts) and rates of change (or slopes) in a set of observed variables. These models are closely related to multilevel models in that observations over time are nested within individuals (see Collins \& Sayer, 2001; Little, Schnabel, \& Baumert, 2000), although there are strengths and limitations associated with each approach. Longitudinal research based on representative samples of known populations is needed in order to confirm the conclusions developed on the basis of the extant literature.

Given the diversity of research strategies in the study of cognitive aging, there is a clear need for exchange among investigators who develop inferences about aging functions on the basis of quite different research designs-from those who work within the quasi-experimental tradition, where depth of measurement is viewed as critical but where external validity concerns are minimized, to those whose work is rooted in the demographic tradition of understanding population processes in which a great deal of emphasis is placed on probability methods of sampling but where measurement takes place in interview settings and is therefore relatively limited.

Taking this diversity into account, the chapters in this section focus on methodological developments in measurement and design issues, including the measurement of cognition in large-scale surveys, the potential for cultural bias in testing instruments, and other recent advances. The second chapter in this section, by Martin Sliwinski and Jacqueline Mogle, "Time-Based and Process-Based Approaches to Analysis of Longitudinal Data," provides an overview of different ways in which researchers have conceptualized change-approaching it either from the point of view of between-person differences or from the perspective of within-person change. They make a distinction between two analytical approaches to the analysis of longitudinal data: (1) time-based approaches, which model change as a function of the passage of time (i.e., correlated change), and (2) process-based approaches, which model change as a direct function of a concurrent or lagged effect of another change process (i.e., coupled change). Both of these approaches, based on multivariate growth curves or time-varying predictor models, can be implemented in structural equation modeling or multilevel modeling software, but they lead to different inferences regarding within-person change. Sliwinski and Mogle's chapter critically examines these approaches and contrasts the strengths and limitations of each for explaining aging-related change and encourages greater use of process-based models because these provide a more direct explanation of aging-related changes as a direct function of other aging-related variables.

Another issue of critical concern involves the periodicity of measurement. Most longitudinal aging studies have relied on successive, widely spaced single-shot assessments to estimate changes in cognitive performance. Such longitudinal studies assume that short-term temporal variations in cognitive performance are small relative to long-term temporal changes (i.e., that there is a large signal-to-noise ratio). If shortterm temporal variability is moderate to high, then single-shot measurements would fail to produce precise estimates of an individual's average cognitive performance. Although the literature on this topic is scant, sufficient empirical evidence exists that establishes intraindividual cognitive variability as a substantial source of performance variability between people, especially in older adults (Hertzog, Dixon, \& Hultsch, 1992; Li, Aggen, Nesselroade, \& Baltes, 1998; Strauss, MacDonald, Hunter, 


\section{2 • INTRODUCTION}

Moll, \& Hultsch, 2002). Thus, sampling just one score at each wave could produce observed change indicating substantial decline, improvement, or stability. Alternatively, obtaining multiple, closely spaced performance assessments at each wave allows local temporal smoothing of data for each individual by averaging across multiple assessments. Another way of thinking about this issue involves the implementation of multiple indicators at each wave that permit the modeling of random error components in models that incorporate true change. By improving measurement precision, such designs will increase statistical power to detect cognitive change at both the individual and aggregate sample levels and permit greater understanding of intraindividual processes within and across different time intervals (e.g., Alwin, Hofer, \& McCammon, 2006).

Shevaun D. Neupert, Robert S. Stawski, and David M. Almeida discuss the utility of intensive measurement protocols in their chapter, "Considerations for Sampling Time in Research on Aging: Examples From Research on Stress and Cognition." They emphasize the importance of intraindividual change and variation in agingrelated processes in addition to between-person differences for understanding short- and longterm processes and discuss how explanatory mechanisms and choices about time sampling are inextricably linked to study results. On the basis of their own work on stress response and measurement of behavioral and biological processes, alternative designs for within-person sampling are critically examined and shown to provide important opportunities and promise for research on aging.

With some important exceptions, cognitive measures are not often included in large-scale survey data collections because it is assumed that reliable assessments are too difficult and time consuming to administer in an interview format using professional interviewers. Instead, most cognitive assessments used in the study of aging have been carried out in a laboratory or clinical setting by trained testers using rather long, time-consuming batteries of questions to assess multiple dimensions of cognitive function. A critical issue of measurement that we believe future studies must address involves the utility and validity of survey measurement of cognitive functioning. If, as we have argued, future research should produce data based on a model of population processes that insists on the use of representative samples of the population, then this raises the question of whether cognitive functioning can be measured in a survey context or whether the survey context must be modified to accommodate the depth of measurement required in psychometric testing. The development of measures of cognitive performance that can be used in survey settings should be given a high priority for research that uses population-based samples. The chapter titled "Cognitive Testing in Large-Scale Surveys: Assessment by Telephone," by Margie E. Lachman and Patricia A. Tun, addresses the set of issues surrounding the assessment of cognitive function in large-scale epidemiological and longitudinal surveys that are more representative of populations of interest than those typically studied in laboratory or clinical settings. These issues focus specifically, among other things, on the advantages and limitations of assessing cognitive function by telephone (see also Herzog \& Wallace, 1997; and Folstein, Folstein, \& McHugh, 1975). The authors conclude their presentation by reiterating the need to incorporate cognitive assessments into contemporary large-scale surveys of aging, health, and well-being.

The final chapter in this section, by Misha Pavel, Holly Jimison, Tamara Hayes, Jeffrey Kaye, Eric Dishman, Katherine Wild, and Devin Williams, "Continuous, Unobtrusive Monitoring for the Assessment of Cognitive Function," focuses on new designs and measurement protocols for the identification of trends and sensitive detection of changes from normative withinperson functioning within natural home environments. The early detection of change processes would enable interventions to be provided early in such processes and help to optimize aging and health-related outcomes. This is a vital, though challenging, area of research that emphasizes physiological and behavioral assessments using new technology for detecting movement and cognitive functioning over the course of normal behaviors. A key idea is that early detection of change must optimally be based on change from 
a within-person baseline, essentially using individuals as their own controls.

\section{Part VII: Integrative Perspectives on Cognitive Aging}

The chapters in Part VII focus on multidisciplinary integration, including life span processes, minority populations, and other factors. The chapter titled "Animal Models of Human Cognitive Aging," by Gerald E. McClearn and David A. Blizard, provides an overview of animal models for understanding basic cognitive processes across the life span. Much of the research on cognition in animals has focused on learning and memory, comparing young and old animals on a variety of tasks. An important feature of animal models is the ability to hold environmental effects relatively constant and to evaluate specific genetic effects and genetic backgrounds in a highly controlled manner. McClearn and Blizard provide insightful perspectives for the use of animal models for identifying complex geneenvironment interaction effects in a multivariate context that will surely augment and inform research on human functioning.

The chapter by Chandra A. Reynolds, "Genetic and Environmental Influences on Cognitive Change," describes findings from twin and adoption studies, emphasizing results from studies that have evaluated outcomes of change in cognitive functioning. A number of longitudinal studies of twins and families provide essential data to describe contributions of genetic and environmental influences and permit tests of alternative hypotheses regarding population individual differences. This is an exciting area of research, and Reynolds summarizes future directions, including the identification of candidate genes and specific environmental effects and complex interactions of genes and environments that are essential next steps for understanding aging-related changes.

Brent J. Small and Cathy L. McEvoy take up the issue of lifestyle activities and maintenance of cognitive function in their chapter, "Does Participation in Cognitive Activities Buffer AgeRelated Cognitive Decline?" Much of what we know about relationships among lifestyle activities and cognitive functioning comes from cross-sectional studies of individuals who differ in age. Small and McEvoy describe two major theoretical perspectives, one referring to the substantive complexity of environments and one focusing on the development of cognitive reserve related to education and occupational attainment. They evaluate empirical results in the context of these two theories and emphasize the importance of longitudinal findings for the evaluation of this and other important influences on cognitive outcomes with age.

The importance of basic cognitive aging research is high given the fundamental role these processes have in maintaining everyday life. Matthias Kliegel, Peter Rendell, and Mareike Altgassen focus on this interplay of basic and applied science and application in their chapter, "The Added Value of an Applied Perspective in Cognitive Gerontology." They demonstrate how basic research and theorizing, in terms of planning and prospective memory, can benefit from taking implications and findings from applied research and real life aspects of behavior seriously. Their chapter provides an important applied element to the chapters included in this volume-an approach that is beginning to have considerable payoff.

The chapter on "Social Resources and Cognitive Function in Older Persons," by Lisa L. Barnes, Kathleen A. Cagney, and Carlos F. Mendes de Leon, begins with the premise that social integration is linked to better physical and mental health and goes on to review the several research traditions that have developed constructs to assess resources that reflect the salutary effects of the level of social integration. To be more specific, three literatures-social networks, social engagement or activity, and social support-point to such an effect for physical and mental health. Too little attention has been paid to the role of social resources and cognitive function. In addition, it is important to distinguish between individual-level social resources and community-level attributes of the social environment, and these authors present some recent data that estimate the relationships among individualand community-level social resources to level of cognitive function in a community-based sample. The chapter concludes with the assertion that because social resources are "readily 


\section{4 • INTRODUCTION}

modifiable," this body of research has implications for the cognitive aging of present cohorts. The authors articulate several unresolved issues, including the need for more research on the effects of community- or contextual-level variables on cognitive function and the importance of understanding the mechanisms that mediate or otherwise explain the association of social resources and cognitive function.

Consistent with these themes, the chapter by Fredda Blanchard-Fields, Michelle Horhota, and Andrew Mienaltowski, "Social Context and Cognition," argues that studies of cognitive aging have not examined how social knowledge, emotions, and motivational factors develop in older age. Because of the lack of attention to these variables, past studies may not accurately reflect the potential range of older adults' skills and knowledge. They find that when contextual variables, such as emotions, personal goals, personal beliefs, and interactive milieu, are taken into account, older adults' functioning often remains intact, suggesting that social factors play a highly important role in age-related cognitive change. Among others, one of the literatures covered in this chapter is the work that has been done on collaborative cognition, which occurs when two (or more) people work together to solve cognitive tasks. This topic is also covered in depth by the following chapter, by Mike Martin and Melanie Wight, "Dyadic Cognition in Old Age: Paradigms, Findings, and Directions." Focusing on pairs of persons both 60 years of age or older, Martin and Wight discuss the paradigms, observed patterns, and explanatory concepts across several performance domains-dyadic memory, dyadic planning, dyadic decision making, dyadic reasoning, and dyadic comprehension. They conclude that a number of problems and puzzles are still remaining to be solved in this area. For example, it is not completely clear whether "dyadic cognition" is all that much better than individual cognition, and the question of whether older dyads are better or worse than young dyads on certain tasks remains unresolved.

The final chapter in this section, "Midlife Cognition: The Association of Personality With Cognition and Risk of Cognitive Impairment," by Sherry L. Willis and Julie Blaskewicz Boron, remind us that aging begins in midlife, if not earlier. They note that although many trait and personality theories of adult development emphasize the stability of individual differences, levels of change are less pronounced in old age. They argue that an examination of the association of personality and intellective factors during midlife is an interesting topic of research and that research examining early antecedents of cognitive risk in old age has suggested that certain personality dimensions may influence the onset of neuron deterioration that may contribute to cognitive impairment. They review the literature on the potential role of personality (e.g., neuroticism) in creating greater risks of cognitive decline in old age.

\section{Part VIII: Future Directions for Research on Cognitive Aging}

In the final section, we provide an overview of promising directions for future research on cognitive aging. Our chapter, "The Future of Cognitive Aging Research," summarizes the issues covered in this handbook for an overall perspective on the priorities that need to be addressed in future work on cognitive aging. Despite the great potential of current theories and methods, there are several serious limitations with the existing data upon which generalizations about cognitive aging rest, raising concerns about projections that may be made about the future of cognitive aging. In fact, the problems with the available data pose a major threat to the credibility of our inferences about age-related differences reported in the social, behavioral, and psychological literatures on cognitive development. Virtually all of our knowledge about age-related changes in cognitive function is based on cross-sectional designs, or on longitudinal studies of relatively short duration from small samples of unknown or questionable representativeness.

Although there are exceptions to this general characterization of the extant literature, most scholars agree that this is a fair description of the state of the current knowledge base. It is therefore critical that we reassess the basis for many of the findings that shape our conclusions about cognitive aging, the optimal designs for studying agerelated change, and the kinds of data we will need for studying cognitive aging in the future. Given 
the many limitations of cross-sectional research emphasizing between-person age differences (Hofer, Flaherty, \& Hoffman, 2006; Hofer \& Sliwinski, 2001), it is generally agreed that one of the most productive approaches to the study of aging and human development involves the collection and analysis of longitudinal data (see Alwin \& Campbell, 2001; Alwin et al., 2006; Hofer \& Sliwinski, 2006). Although much of our knowledge and theoretical models have been based on results from cross-sectional research, there are an increasing number of studies that are longitudinal in design (Hofer \& Piccinin, 2007; Schaie \& Hofer, 2002) that can be used to evaluate current theories and hypotheses and provide a strong foundation for new theoretical developments. However, most of these studies span a relatively short period of time beginning in later life (e.g., age 65), often limiting the explanatory variables of cognitive change to static individualdifference variables or retrospective measurements that may be unreliable. More longitudinal research over broad periods of the life span is needed to confirm patterns of cognitive change in middle and older age and as a function of events and processes earlier in the life span. When combined with sampling designs that are adequate for the generalization of findings to populations of interests, new longitudinal investigations can take advantage of the significant improvements that have been made in studying change within individuals as they age. We argue, with the authors of The Aging Mind (NRC, 2000), that future research will need to pay closer attention to sampling design issues in order to meet more rigorous standards for generalization to populations of interest and for the sensitive measurement of within-person change.

The NRC committee report on "Future Directions" was quite explicit with regard to the requirements of future research on cognitive aging. To achieve the objectives of the recommended research initiatives, the report argued:

It will be necessary to expand the use of large-scale multivariate, longitudinal studies ... to expand and improve on previous longitudinal research by including variables reflecting high-resolution cognitive and neural measures; indicators of health status and sensory-motor functioning; and measures of relevant life experience. (NRC, 2000, p. 52)
Furthermore, it is also "important to examine a broad representative sample of the population, sometimes over-sampling in subgroups whose health status or responses to life experiences are expected to illuminate important theoretical questions, and to encompass a wide age range" (NRC, 2000, p. 53). Finally, the report argued that

by following individuals into very old age, promising new findings suggesting the existence of unexpected linkages between cognitive functioning and survival could be investigated... [and] the conjunction of improved measurement, advances in modeling, and the comprehensive collection of longitudinal data on cognitive functioning and associated factors can have a synergistic effect in advancing knowledge. (NRC, 2000, p. 53)

Our discussion of these issues in the final chapter expands upon these ideas and synthesizes the recommendations made by the many scientists represented in this handbook for the future of cognitive aging research.

\section{NOTES}

1. Scientific revolutions can be recognized by two essential characteristics: (1) unprecedented achievements that attract an enduring group of adherents away from competing perspectives and (2) development of new problems and puzzles for new generations of scientists to solve (Kuhn, 1962, p. 10).

2. The Healthy Brain workshop was first held July 9-10, 2001, in Bethesda, MD, and has thereupon held additional meetings (see http://trans.nih.gov/ CEHP/workshop.htm).

\section{REFERENCES}

Alwin, D. F., et al. (2008). The aging mind in social and historical context. Unpublished manuscript, Center on Population Health and Aging, Pennsylvania State University.

Alwin, D. F., \& Campbell, R. T. (2001). Longitudinal methods in the study of human development and aging. In R. H. Binstock \& L. K. George (Eds.), Handbook of aging and the social sciences (pp. 22-43). New York: Academic Press.

Alwin, D. F., Hofer, S. M., \& McCammon, R. J. (2006). Modeling the effects of time: Integrating demographic and developmental perspectives. 


\section{6 • INTRODUCTION}

In R. H. Binstock \& L. K. George (Eds.), Handbook of aging and the social sciences (pp. 20-38). New York: Academic Press.

Alwin, D. F., \& Wray, L. A. (2005). A life-span developmental perspective on social status and health. Journal of Gerontology: Social Science, $60 B$ (Special Issue II), 7-14.

Anstey, K. J., \& Christensen, H. (2000). Education, activity, health, blood pressure and Apolipoprotein $\mathrm{E}$ as predictors of cognitive change in old age: A review. Gerontology, 46, 163-177.

Anstey, K. J., Hofer, S. M., \& Luszcz, M. A. (2003a). Cross-sectional and longitudinal patterns of dedifferentiation in late life cognitive and sensory function: The effects of age, ability, attrition, and occasions of measurement. Journal of Experimental Aging Research, 22, 245-266.

Anstey, K. J., Hofer, S. M., \& Luszcz, M. A. (2003b). A latent growth curve analysis of late life cognitive and sensory function over eight years: Evidence for specific and common factors underlying change. Psychology and Aging, 18, 714-726.

Anstey, K. J., Luszcz, M. A., \& Sanchez, L. (2001). A reevaluation of the common factor theory of shared variance among age, sensory function, and cognitive function in older adults. Journal of Gerontology: Psychological Sciences, 56B, P3-P11.

Anstey, K. J., Windsor, T. D., Jorm, A. F., Christensen, H., \& Rodgers, B. (2003). Association of pulmonary function with cognitive performance in early, middle, and late adulthood. Gerontology, 50, 230-234.

Baltes, P. B., \& Lindenberger, U. (1997). Emergence of a powerful connection between sensory and cognitive functions across the adult life span: A new window to the study of cognitive aging. Psychology and Aging, 12, 12-21.

Baltes, P. B., \& Mayer, K. U. (1999). The Berlin Aging Study: Aging from 70 to 100. Cambridge, UK: Cambridge University Press.

Baltes, P. B., \& Schaie, K. W. (1976). On the plasticity of intelligence in adulthood and old age: Where Horn and Donaldson fail. American Psychologist, 31, 720-725.

Bandura, A. (1989). Regulation of cognitive processes through perceived self-efficacy. Developmental Psychology, 25, 729-735.

Birren, J. E., \& Fisher, L. M. (1995). Aging and speed of behavior: Possible consequences for psychological functioning. Annual Review of Psychology, 46, 329-353.

Birren, J. E., \& Morrison, D. F. (1961). Analysis of the WAIS subtests in relation to age and education. Journal of Gerontology, 16, 363-369.

Blanchard-Fields, F., \& Hess, T. (1996). Perspectives on cognitive change in adulthood and aging. Boston: McGraw-Hill.

Bloom, B. S. (1964). Stability and change in human characteristics. New York: Wiley.

Britton, A., Singh-Manoux, A., \& Marmot, M. (2004). Alcohol consumption and cognitive function in the Whitehall II Study. American Journal of Epidemiology, 160, 240-247.

Brookmeyer, R., \& Gray, S. (2000). Methods for projecting the incidence and prevalence of chronic diseases in ageing populations: Application to Alzheimer's disease. Statistics in Medicine, 19, 1481-1493.

Brookmeyer, R., Gray, S., \& Kawas, C. (1998). Projections of Alzheimer's disease in the United States and the public health impact of delaying disease onset. American Journal of Public Health, 88, 1337-1342.

Brown, S. C., \& Park, D. C. (2003). Theoretical models of cognitive aging and implications for translational research in medicine. The Gerontologist, 43, S57-S67.

Cattell, R. B. (1941). Some theoretical issues in adult intelligence testing. Psychological Bulletin, 38, 592.

Cattell, R. B. (1971). Abilities: Their structure, growth and action. Boston: Houghton Mifflin.

Cerella, J. (1985). Information processing rates in the elderly. Psychological Bulletin, 98, 67-83.

Chen, W.-T., Wang, P.-N., Wang, S.-J., Fuh, J.-L., Lin, K.-N., \& Liu, H.-C. (2003). Smoking and cognitive performance in the community elderly: A longitudinal study. Journal of Geriatric Psychiatry and Neurology, 16, 18-22.

Christensen, H., Hofer, S. M., Mackinnon, A. J., Korten, A. E., Jorm, A. F., \& Henderson, A. S. (2001). Age is no kinder to the better educated: Absence of an association investigated using latent growth techniques in a community sample. Psychological Medicine, 31, 15-28.

Christensen, H., Korten, A. E., Jorm, A. F., Henderson, A. S., Jacomb, P. A., Rodgers, B., \& Mackinnon, A. J. (1997). Education and decline in cognitive performance: Compensatory but not protective. International Journal of Geriatric Psychiatry, 12, 323-330. 
Churchill, J. D., Galvez, R., Colcombe, S., Swain, R. A., Kramer, A. F., \& Greenough, W. T. (2002). Exercise, experience, and the aging brain. Neurobiology of Aging, 23, 941-955.

Collins, L. M., \& Sayer, A. G. (Eds.). (2001). New methods for the analysis of change. Washington, DC: American Psychological Association.

Corrêa-Leite, M. L., Nicolosi, A., Cristina, S., Hauser, W. A., \& Nappi, G. (2001). Nutrition and cognitive deficit in the elderly: A population study. European Journal of Clinical Nutrition, 55, 1053-1058.

Cosway, R., Strachan, M. W. J., Dougall, A., Frier, B. M., \& Deary, I. J. (2001). Cognitive function and information processing in type 2 diabetes. Diabetic Medicine, 18, 803-810.

Craik, F., \& Byrd, M. (1982). Aging and cognitive deficits: The role of attentional resources. In F. Craik \& S. Trehub (Eds.), Aging and cognitive processes (pp. 191-211). New York: Plenum.

Crooks, V. C., Buckwalter, J. G., \& Petitti, D. B. (2003). Diabetes mellitus and cognitive performance in older women. Annals of Epidemiology, 13, 613-619.

Dannefer, W. D. (1984). Adult development and social theory: A paradigmatic reappraisal. American Sociological Review, 49, 100-116.

Dannefer, W. D. (1987). Aging as intracohort differentiation: Accentuation, the Matthew effect, and the life course. Sociological Forum, 2, 211-236.

Dannefer, W. D. (1988). What's in a name? An account of the neglect of variability in the study of aging. In J. E. Birren \& V. L. Bengtson (Eds.), Emergent theories of aging (pp. 356-384). New York: Springer.

Dannefer, W. D. (2003). Cumulative advantage/ disadvantage and the life course: Cross-fertilizing age and social science theory. Journal of Gerontology: Social Sciences, 58B, S327-S357.

Dik, M., Deeg, D. J., Visser, M., \& Jonker, C. (2003). Early life physical activity and cognition at old age. Journal of Clinical and Experimental Neuropsychology, 25, 643-653.

Dixon, R. A. (1999). The concept of gains in cognitive aging. In D. C. Park \& N. Schwarz (Eds.), Cognition, aging, and self-reports (pp. 71-92). Philadelphia: Taylor \& Francis.

Dufouil, C., Alpérovitch, A., \& Tzourio, C. (2003). Influence of education on the relationship between white matter lesions and cognition. Neurology, 60, 831-836.
Emery, C. F., Shermer, R. L., Hauchk, E. R., Hsiao, E. T., \& MacIntyre, N. R. (2003). Cognitive and psychological outcomes of exercise in a one-year follow-up study of patients with chronic obstructive pulmonary disease. Health Psychology, 22, 598-604.

Espeland, M. A., Gu, L., Masaki, K. H., Langer, R. D., Coker, L. H., Stefanick, M. L., et al. (2005). Association between reported alcohol intake and cognition: Results from the Women's Health Initiative Memory Study. American Journal of Epidemiology, 161, 228-238.

Evans, D. A., Scherr, P. A., Cook, N. R., Albert, M. S., Funkenstein, H. H., Beckett, L. A., et al. (1992). The impact of Alzheimer's disease in the United States population. In R. M. Suzman, D. P. Willis, \& K. G. Manton (Eds.), The oldest old (pp. 283-299). New York: Oxford University Press.

Finch, C. E., \& Crimmins, E. M. (2004, September 17). Inflammatory exposure and historical changes in human life-spans. Science, 305, 1736-1739.

Fisher, D. L. (2000). Cognitive aging and adaptive technologies. In P. C. Stern \& L. L. Carstensen (Eds.), The aging mind: Opportunities in cognitive research (pp. 166-188). Washington, DC: National Academy Press.

Fiske, A. P., Kitiyama, S., Markus, H. R., \& Nisbett, R. E. (1998). The cultural matrix of social psychology. In D. T. Gilbert, S. T. Fiske, \& G. Lindzey (Eds.), The handbook of social psychology (4th ed., pp. 915-981). Boston: McGraw-Hill.

Folstein, M. F., Folstein, S. E., \& McHugh, P. R. (1975). Mini-Mental State: A practical method for grading the cognitive state of patients for the clinician. Journal of Psychiatric Research, 12, 189-198.

Geroldi, C., Ferrucci, L., Bandinelli, S., Cavazzini, C., Zanetti, O, Guralnik, J., \& Frisoni, G. B. (2003). Mild cognitive deterioration with subcortical features: Prevalence, clinical characteristics, and association with cardiovascular risk factors in community-dwelling older persons (The InCHIANTI Study). Journal of the American Geriatrics Society, 51, 1064-1071.

Haan, M., Shemanski, L., Jagust, W., Manolio, T., \& Kuller, L. (1999). The role of APOE epsilon 4 modulating effects of other risk factors for cognitive decline in elderly persons. Journal of the American Medical Association, 282, 40-46.

Hall, C. B., Lipton, R. B., Sliwinski, M. J., \& Stewart, W. F. (2000). A change point model for estimating onset of cognitive decline in preclinical 


\section{8 - INTRODUCTION}

Alzheimer's disease. Statistics in Medicine, 19, 1555-1566.

Harris, C. R., Albaugh, B., Goldman, D., \& Enoch, M. A. (2003). Neurocognitive impairment due to chronic alcohol consumption in an American Indian community. Journal of the Study of Alcohol, 64, 458-466.

Hassing, L. B., Grant, M. D., Hofer, S. M., Pedersen, N. L., Nilsson, S. E., Berg, S., et al. (2004). Type 2 diabetes mellitus contributes to cognitive change in the oldest old: A longitudinal populationbased study. Journal of the International Neuropsychological Society, 4, 599-607.

Hassing, L. B., Hofer, S. M., Nilsson, S. E., Berg, S., Pedersen, N. L., McClearn, G. E., \& Johansson, B. (2004). Comorbid type 2 diabetes mellitus and hypertension exacerbates cognitive decline: Evidence from a longitudinal study. Age and Aging, 33, 355-361.

Hassing, L. B., Johansson, B., Berg, S., Nilsson, S. E., Pedersen, N. L., Hofer, S. M., \& McClearn, G. E. (2002). Terminal decline and markers of cerebro- and cardiovascular disease: Findings from a longitudinal study of the oldest old. Journal of Gerontology: Psychological Sciences, 57B, P268-P276.

Hendrie, H. C., Albert, M. S., Butters, M. A., Gao, S., Knopman, D. S., Launer, L. J., et al. (2006). The NIH Cognitive and Emotional Health Project: Report of the critical evaluation study committee. Alzheimer's \& Dementia, 2, 12-32.

Hertzog, C., Dixon, R., \& Hultsch, D. (1992). Intraindividual change in text recall of the elderly. Brain and Language, 42, 248-269.

Hertzog, C., \& Schaie, K. W. (1986). Stability and change in adult intelligence: I. Analysis of longitudinal covariance structures. Psychology and Aging, 1, 159-171.

Hertzog, C., \& Schaie, K. W. (1988). Stability and change in adult intelligence: 2. Simultaneous Analysis of longitudinal means and covariance structures. Psychology and Aging, 3, 122-130.

Herzog, A. R., \& Wallace, R. B. (1997). Measures of cognitive functioning in the AHEAD Study. Journals of Gerontology Series B: Psychological Sciences and Social Sciences, 52B, 37-48.

Heyn, P., Abreu, B. C., \& Ottenbacher, K. J. (2004). The effects of exercise training on elderly persons with cognitive impairment and dementia: A meta-analysis. Archives of Physical Medicine and Rehabilitation, 85, 1694-1704.

Hill, R. D., Nilsson, L. G., Nyberg, L., \& Bäckman, L. (2003). Cigarette smoking and cognitive performance in healthy Swedish adults. Age and Ageing, 32, 548-550.

Hillman, C. H., Belopolsky, A. V., Snook, E. M., Kramer, A. F., \& McAuley, E. (2004). Physical activity and executive control: Implications for increased cognitive health during older adulthood. Research Quarterly for Exercise and Sport, 75, 176-185.

Hofer, S. M., Berg, S., \& Era, P. (2003). Evaluating the interdependence of aging-related changes in visual and auditory acuity, balance, and cognitive functioning. Psychology and Aging, 18, 285-305.

Hofer, S. M., Flaherty, B. P., \& Hoffman, L. (2006). Cross-sectional analysis of time-dependent data: Problems of mean-induced association in ageheterogeneous samples and an alternative method based on sequential narrow age-cohorts. Multivariate Behavioral Research, 41, 165-187.

Hofer, S. M., \& Piccinin, A. M. (2007). Longitudinal studies. In J. E. Birren (Ed.), Encyclopedia of gerontology: Age, aging, and the aged (2nd ed.). Oxford, UK: Elsevier.

Hofer, S. M., \& Sliwinski, M. J. (2001). Understanding ageing: An evaluation of research designs for assessing the interdependence of ageing-related changes. Gerontology, 47, 341-352.

Hofer, S. M., \& Sliwinski, M. J. (2006). Design and analysis of longitudinal studies of aging. In J. E. Birren \& K. W. Schaie (Eds.), Handbook of the psychology of aging (6th ed., pp. 15-37). San Diego, CA: Academic Press.

Horn, J. L. (1965). Fluid and crystallized intelligence: A factor analytic study of the structure among primary mental abilities. Unpublished doctoral dissertation, University of Illinois.

Horn, J. L., \& Cattell, R. B. (1966). Refinement and test of the theory of fluid and crystallized general intelligences. Journal of Educational Psychology, 57, 253-270.

Horn, J. L., \& Donaldson, G. (1977). Faith is not enough: A response to the Baltes-Schaie claim that intelligence does not wane. American Psychologist, 32, 369-373.

Horn, J. L., \& Donaldson, G. (1980). Cognitive development in adulthood. In O. G. Brim, Jr. \& J. Kagan (Eds.), Constancy and change in 
human development (pp. 445-529). Cambridge, MA: Harvard University Press.

Juster, F. T., \& Suzman, R. (1995). An overview of the Health and Retirement Study. Journal of Human Resources, 30, S7-S56.

Kalmijn, S., van Boxtel, M. P. J., \& Verschuren, M. W. (2002). Cigarette smoking and alcohol consumption in relation to cognitive performance. American Journal of Epidemiology, 156, 936-944.

Kawas, C. H., \& Brookmeyer, R. (2001). Aging and the public health: Effects of dementia [Editorial]. New England Journal of Medicine, 344, 1160-1161.

Kitayama, S. (2000). Cultural variations in cognition: Implications for aging research. In P. C. Stern \& L. L. Carstensen (Eds.), The aging mind: Opportunities in cognitive research (pp. 218-237). Washington, DC: National Academy Press.

Kraemer, H. C., Yesavage, J. A., Taylor, J. L., \& Kupfer, D. (2000). How can we learn about developmental processes from cross-sectional studies, or can we? American Journal of Psychiatry, 157, 163-171.

Kuhn, T. S. (1962). The structure of scientific revolutions. Chicago: University of Chicago Press.

Leroi, I., Sheppard, J. M., \& Lyketsos, C. G. (2002). Cognitive function after 11.5 years of alcohol use. American Journal of Epidemiology, 156, 747-752.

Li, S.-C., Aggen, S. H., Nesselroade, J. R., \& Baltes, P. B. (1998). Short-term fluctuations in elderly people's sensorimotor functioning predict text and spatial memory performance: The MacArthur Successful Aging Studies. Gerontology, 47, 100-116.

Lindenberger, U., \& Baltes, P. B. (1994). Sensory functioning and intelligence in old age: A strong connection, Psychology and Aging, 9, 339-355.

Little, T. D., Schnabel, K. U., \& Baumert, J. (Eds.). (2000). Modeling longitudinal and multilevel data. Mahwah, NJ: Lawrence Erlbaum.

Lorge, I. (1956). Aging and intelligence. Journal of Chronic Diseases, 412, 131-139.

Myerson, J., Hale, S., Wagstaff, D., Poon, L. W., \& Smith, G. A. (1990). The information-loss model: A mathematical theory of age-related cognitive slowing. Psychological Review, 97, 475-487.

National Institute on Aging, National Advisory Council on Aging, Behavioral and Social Research (BSR) Program Review Committee.
(2004). BSR Review Committee report (revised August 10, 2004). Retrieved August 3, 2007, from http://www.nia.nih.gov/NR/rdonlyres/2EA2 C923-8418-4CF1-8D2A-66B6BEDBB321/2308/ BSRReviewReportFINAL.pdf

National Research Council. (2000). The aging mind: Opportunities in cognitive research. Committee on Future Directions for Cognitive Research on Aging. Paul C. Stern and Laura L. Carstensen, Editors. Commission on Behavioral and Social Sciences and Education. Washington, DC: National Academy Press.

National Research Council. (2007). A strategy for assessing science: Behavioral and social research on aging. Committee on Assessing Behavioral and Social Science Research on Aging. Irwin Feller and Paul C. Stern, Editors. Center for Studies of Behavior and Development, Division of Behavioral and Social Sciences and Education. Washington, DC: National Academy Press.

O'Rand, A. M. (1996). The precious and the precocious: Understanding cumulative disadvantage and cumulative advantage over the life course. The Gerontologist, 36, 230-238.

Ostir, G. V., Raji, M. A., Ottenbacher, K. J., Markides, K. S., \& Goodwin, J. S. (2003). Cognitive function and incidence of stroke in older Mexican Americans. Journal of Gerontology: Medical Sciences, 58A, 531-535.

Park, D. C. (1999). Cognitive aging, processing resources, and self-report. In N. Schwarz, D. Park, B. Knäuper, \& S. Sudman (Eds.), Cognition, aging, and self-reports (pp. 45-69). Philadelphia: Psychology Press.

Park, D. C., Smith, A. D., Lautenschlager, G., Earles, J., Frieske, D., Zwahr, M., \& Gaines, C. (1996). Mediators of long-term memory performance across the life-span. Psychology and Aging, 11, 621-637.

Pavlik, V. N., Hyman, D. J., \& Doody, R. (2005). Cardiovascular risk factors and cognitive function in adults 30-59 years of age (NHANES III). Neuroepidemiology, 24, 42-50.

Perreira, K. M., \& Sloan, F. A. (2002). Excess alcohol consumption and health outcomes: A 6-year follow-up of men over age 50 from the Health and Retirement Study. Addiction, 97, 301-310.

Razani, J., Boone, K., Lesser, I., \& Weiss, D. (2004). Effects of cigarette smoking history on cognitive 


\section{0 - INTRODUCTION}

functioning in healthy older adults. American Journal of Geriatric Psychiatry, 12, 404-411.

Richards, M., Jarvis, M. J., Thompson, N., \& Wadsworth, M. E. J. (2003). Cigarette smoking and cognitive decline in midlife: Evidence from a prospective birth cohort study. American Journal of Public Health, 93, 994-998.

Rowe, J. W., \& Kahn, R. L. (1998). Successful aging. New York: Pantheon.

Rubin, E. H., Storandt, M., Miller, J. P., Kinscherf, D. A.,Grant, E. A., Morris, J. C., \& Berg, L. (1998). A prospective study of cognitive function and onset of dementia in cognitively healthy elders. Archives of Neurology, 55, 395-401.

Salthouse, T. A. (1991). Theoretical perspectives on cognitive aging. Hillsdale, $\mathrm{NJ}$ : Lawrence Erlbaum.

Salthouse, T. A. (1993). Speed and knowledge as determinants of adult age differences in verbal tasks. Journal of Gerontology: Psychological Sciences, 48, P29-P36.

Salthouse, T. A. (1996a). Constraints on theories of cognitive aging. Psychonomic Bulletin and Review, 3, 287-299.

Salthouse, T. A. (1996b). The processing-speed theory of adult age differences in cognition. Psychological Review, 103, 403-428.

Salthouse, T. A. (1999). Pressing issues in cognitive aging. In D. C. Park \& N. Schwarz (Eds.), Cognition, aging, and self-reports (pp. 185-198). Philadelphia: Taylor \& Francis.

Schaie, K. W. (1983). The Seattle Longitudinal Study: A 21-year exploration of psychometric intelligence in adulthood. In K. W. Schaie (Ed.), Longitudinal studies of adult psychological development (pp. 24-49). New York: Guilford Press.

Schaie, K. W. (1984). Historical time and cohort effects. In K. A. McCloskey \& H. W. Reese (Eds.), Life-span developmental psychology: Historical and generational effects (pp. 1-15). New York: Academic Press.

Schaie, K. W. (1989). Individual differences in rate of cognitive change in adulthood. In V. L. Bengtson $\&$ K. W. Schaie (Eds.), The course of later life: Research and reflections (pp. 65-85). New York: Springer.

Schaie, K. W. (1990). Intellectual development in adulthood. In J. E. Birren \& K. W. Schaie (Eds.), Handbook of the psychology of aging (3rd ed., pp. 291-309). San Diego, CA: Academic Press.
Schaie, K. W. (1994). The course of adult intellectual development. American Psychologist, 49, 304-313.

Schaie, K. W. (1996). Intellectual development in adulthood: The Seattle longitudinal study. Cambridge, UK: Cambridge University Press.

Schaie, K. W., \& Hertzog, C. (1983). Fourteen-year cohort-sequential studies of adult intelligence. Developmental Psychology, 19, 531-543.

Schaie, K. W., \& Hofer, S. M. (2002). Longitudinal studies in aging research. In J. E. Birren \& K. W. Schaie (Eds.), Handbook of the psychology of aging (5th ed., pp. 53-77). San Diego, CA: Academic Press.

Schaie, K. W., Willis, S. L., \& Pennak, S. (2005). An historical framework for cohort differences in intelligence. Research in Human Development, 2, 43-67.

Schinka, J. A., Belanger, H., Mortimer, J. A., \& Borenstein-Graves, A. (2003). Effects of the use of alcohol and cigarettes on cognition in elderly African American adults. Journal of International Neuropsychology, 9, 690-697.

Schuit, A. J., Feskens, E. J., Launer, L. J., \& Kromhout, D. (2001). Physical activity and cognitive decline: The role of the apolipoprotein e4 allele. Medical Science and Sports Exercise, 33, 772-777.

Sliwinski, M. J., Hofer, S. M., \& Hall, C. (2003). Correlated and coupled cognitive change in older adults with and without clinical dementia. Psychology and Aging, 18, 672-683.

Sliwinski, M. J., Hofer, S. M., Hall, C., Bushke, H., \& Lipton, R. B. (2003). Modeling memory decline in older adults: The importance of preclinical dementia, attrition and chronological age. Psychology and Aging, 18, 658-671.

Sliwinski, M. J., Lipton, R. B., Buschke, H., \& Stewart, W. F. (1996). The effect of pre-clinical dementia on estimates of normal cognitive function in aging. Journal of Gerontology: Psychological Sciences, 51B, P217-P225.

Strauss, E., MacDonald, S. W., Hunter, M., Moll, A., $\&$ Hultsch, D. F. (2002). Intraindividual variability in cognitive performance in three groups of older adults: Cross-domain links to physical status and self-perceived affect and beliefs. Journal of the International Neuropsychological Society, 8, 893-906.

Suzman, R. M. (2004). Research on population aging at NIA: Retrospect and prospect. In L. J. Waite (Ed.), Aging, health, and public policy: Demographic 
and economic perspectives (pp. 239-264; supplement to Vol. 30, Population and Development Review). New York: Population Council.

Suzman, R. M., Willis, D. P., \& Manton, K. G. (Eds.). (1992). The oldest old. New York: Oxford University Press.

United Nations. (2002). World population ageing: 1950-2050. New York: Author.

Vaupel, J. W., \& Yashin, A. I. (1985). Heterogeneity's ruses: Some surprising effects of selection on population dynamics. The American Statistician, 39, 176-185.

Verbrugge, L. M., \& Jette, A. M. (1994). The disablement process. Social Science and Medicine, 38, $1-14$.

Waldstein, S. R. (2000). Health effects on cognitive aging. In P. C. Stern \& L. L. Carstensen (Eds.), The aging mind: Opportunities in cognitive research (pp. 189-217). Committee on Future Directions for Cognitive Research on Aging, National Research Council. Washington, DC: National Academy Press.

Waldstein, S. R., \& Elias, M. F. (Eds.). (2001). Neuropsychology of cardiovascular disease. Mahwah, NJ: Lawrence Erlbaum.

Weiss, K. M. (1990). The biodemography of variation in human frailty. Demography, 27, 185-206.

Willis, S. L. (1990). Contributions of cognitive training research to understanding late life potential. In M. Perlmutter (Ed.), Late life potential (pp. 25-42). Washington, DC: Gerontological Society of America.

Willis, S. L., \& Schaie, K. W. (2006). Cognitive functioning in the Baby Boomers: Longitudinal and cohort effects. In S. K. Whitbourne \& S. L. Willis (Eds.), The Baby Boomers grow up: Contemporary perspectives on midlife (pp. 205-234). Mahwah, NJ: Lawrence Erlbaum.

Willis, S. L., Tennstedt, S. L., Marsiske, M., Ball, K., Elias, J., Koepke, K. M., et al. (2006). Long-term effects of cognitive training on everyday functional outcomes in older adults: The ACTIVE Study. Journal of the American Medical Association, 296, 2805-2814.

Wilson, R. S., Bennett, D. A., \& Swarzendruber, A. (1997). Age-related change in cognitive function. In P. D. Nussbaum (Ed.), Handbook of neuropsychology and aging (pp. 7-14). New York: Plenum. Wilson, R. S., Mendes de Leon, C. F., Bennett, D. A., Bienias, J. L., \& Evans, D. A. (2004). Depressive symptoms and cognitive decline in a community population of older persons. Journal of Neurology and Neurosurgical Psychiatry, 75, 126-129.

Wray, L. A., \& Blaum, C. S. (2001). Explaining the role of sex on disability: A population-based study. The Gerontologist, 41, 499-510.

Yaffe, K., Linquist, K., Penninx, B. W., Simonsick, E. M., Pahor, M., Dritchevsky, S., et al. (2003). Inflammatory markers and cognition in wellfunctioning African-American and White elders. Neurology, 61, 76-80.

Zhang, Y., Heeren, T., \& Ellison, R. C. (2005). Education modifies the effect of alcohol on memory impairment: The third National Health and Nutrition Examination Survey. Neuroepidemiology, 24, 63-69.

Zhou, H., Deng, J., Li, J., Wang, Y., Zhang, M., \& He, H. (2003). Study of the relationship between cigarette smoking, alcohol drinking and cognitive impairment among elderly people in China. Age and Ageing, 32, 205-210. 
01-Hofer-45484.qxd 2/26/2008 11:59 AM Page 32 


\section{INTEGRATIVE}

\section{Theoretical Perspectives}

